\title{
Sectoral Heterogeneity in the Employment Effects of Job Creation Schemes in Germany*
}

\author{
Marco Caliendo ${ }^{\dagger}$ Reinhard Hujer ${ }^{\ddagger}$ and Stephan L. Thomsen ${ }^{\S}$ \\ *DIW, Berlin and IZA, Bonn \\ $\dagger$ †.W.Goethe-University, Frankfurt/Main, IZA, Bonn, ZEW, Mannheim \\ $\ddagger$ J.W.Goethe-University, Frankfurt/Main
}

Revised version: October 26, 2005

\begin{abstract}
Job creation schemes (JCS) have been one important programme of active labour market policy in Germany aiming at the re-integration of hard-to-place unemployed individuals into regular employment. In contrast to earlier evaluation studies of these programmes based on survey data, we use administrative data containing more than 11,000 participants for our analysis and hence, can take effect heterogeneity explicitly into account. We focus on effect heterogeneity caused by differences in the implementation of programmes (economic sector, types of support and implementing institutions). The results are rather discouraging and show that in general, JCS are unable to improve the re-integration chances of participants into regular employment.
\end{abstract}

Keywords: Evaluation - Job Creation Schemes - Employment Effects - Sectoral Heterogeneity

JEL Classification: H43, J68, C13

\footnotetext{
*The authors thank two anonymous referees for valuable comments which helped to improve the paper. Financial support of the Institute for Employment Research (IAB) within the project 'Effects of Job Creation and Structural Adjustment Schemes' is gratefully acknowledged. The usual disclaimer applies. A supplementary appendix to this paper is available on request from the authors and can also be downloaded under http:/www.wiwi.uni-frankfurt.de/professoren/hujer/papers/sectoral_anc_appendix.pdf. A previous version of this paper circulated as 'Individual Employment Effects of Job Creation Schemes in Germany with Respect to Sectoral Heterogeneity'.

Corresponding author: Marco Caliendo, DIW Berlin, Dep. of Public Economics, Königin-Luise-Str. 5, 14195 Berlin, phone: +49-3089789-154, fax: +49-30-89789-9154.

${ }^{\dagger}$ Marco Caliendo is Senior Research Associate at the German Institute for Economic Research (DIW) in Berlin and Research Fellow of the IZA, Bonn, e-mail: mcaliendo@diw.de.

${ }^{\ddagger}$ Reinhard Hujer is Professor of Statistics and Econometrics at the J.W.Goethe-University of Frankfurt/Main, and Research Fellow of the IZA, Bonn and the ZEW, Mannheim, e-mail: hujer@wiwi.uni-frankfurt.de.

${ }^{\S}$ Stephan L. Thomsen is Research Assistant at the Institute of Statistics and Econometrics, J.W.Goethe-University of Frankfurt/Main, e-mail: sthomsen@ wiwi.uni-frankfurt.de.
} 


\section{Introduction}

The purpose of active labour market policy (ALMP) in Germany is the permanent integration of unemployed individuals into regular employment. Several types of programmes are offered by the Federal Employment Agency (FEA) which aim to promote human capital transfer, qualification, social stabilisation and an increase of the individual mobility. Although substantial sums have been spent on these programmes in recent years, their success has been questioned, since unemployment in Germany is still rising. Job creation schemes (JCS) have been the second most important ALMP programme after vocational training in the late 1990s and early 2000s in terms of the number of individuals promoted and the amount spent. The measures are a form of subsidised employment for unemployed persons with disadvantages on the labour market, and aim at the stabilisation and qualification of these individuals. Programmes have to be of value to society and additional in nature, which means that only those activities are promoted that could not be executed without the subsidy. Even though this is understandable in order to avoid substitution effects, it is also a drawback since the occupations are not allowed to offer practical experiences which are comparable to regular employment. Further criticism arises because JCS lack explicit qualificational elements leading, e.g. to a formal degree. Therefore, their value in terms of increasing the re-integration of unemployed persons into regular employment has to be evaluated thoroughly.

Such a thorough evaluation of JCS (but also of other ALMP programmes) has long been impossible in Germany, since the available survey data sets that comprise information on JCS, such as the Labour Market Monitors for East Germany and Saxony-Anhalt, contain a relatively small number of participants only and concentrate on East Germany. In addition, due to the small numbers of observations, earlier studies were only able to estimate mean effects. Consequently, effect heterogeneity could not be taken into account properly, e.g. by estimating the effects for sub-groups of the labour market. Hence, drawing policy-relevant conclusions (for sub-groups as well as for West Germany) out of those evaluations is problematic. The picture of the effects in the earlier studies is mixed. Whereas, e.g. Steiner and Kraus (1995) find short-term positive effects for men in East Germany, but no significant effects for women, the extended analysis in Kraus, Puhani and Steiner (2000) results in negative effects for the individuals participating. In line with this finding are the results of Hübler (1997), who states that the programmes do not achieve the expected positive impacts. In contrast, Eichler and Lechner (2002), who analyse the effects for Saxony-Anhalt, find a reduction of unemployment for participants. Thus, no clear tendency in the effects could be revealed from the findings of the published results for Germany.

However, with the introduction of the new legislation for ALMP in 1998 (Sozialgesetzbuch III, Social Code III), the output evaluation of all ALMP instruments became mandatory. Subsequently, administrative 
data has been made available for researchers making it possible to evaluate the effects of JCS (see e.g. Hujer, Caliendo and Thomsen 2004) but also of vocational training programmes ${ }^{1}$ (see Lechner, Miquel and Wunsch 2005a, 2005b and Fitzenberger and Speckesser 2005). The major advantage of this administrative data is that it contains a large number of participants, allowing effect heterogeneity to be taken explicitly into account.

Effects of JCS may be expected to be heterogeneous for several reasons. To give an example, the effects of the programme may differ depending on the unemployed person's situation in the labour market, i.e. the individual labour market prospects, and the conditions of the labour market environment. In a previous study (see Caliendo, Hujer and Thomsen 2005), we focussed on individual, group-specific and regional effect heterogeneity and our results showed that the average effects for the participating individuals are disappointing. For most of the groups we found insignificant or even negative effects. Only for long-term unemployed persons did these programmes improve the employment chances.

Moreover, since occupations in job creation schemes comprise activities in different sectors of the economy, it is likely that their effectiveness varies between sectors. In addition, as eligibility for JCS is determined by the unemployment duration and not a certain qualification level (as for example for vocational training programmes) the differences in the implementation of the programmes may explain some important effect heterogeneity. ${ }^{2}$ Identifying possible sources of good (or bad) effects might help to improve the design and implementation of these programmes in the future. We will analyse three sources of effect heterogeneity in this paper. First, we will investigate the variation of the effects according to the economic sector in which the JCS is accomplished. Based on the nine different economic sectors in which JCS are implemented, we concentrate on the four most important ones, i.e. Agriculture, Construction AND INDUSTRy, ComMUNITY SERVICES and OfFICE AND SERVICES. The remaining sectors are summarised in the category OTHER. Since the occupations in these sectors differ substantially and provide very different working experiences, we expect different effects here as well. However, it is a priori unclear which types of occupation improve the employment chances of individuals most. Second, we evaluate the effects with respect to the institutions implementing the programmes. Due to the small numbers of programmes supported by private businesses, we exclude them from the analysis and concentrate on PUBLIC and NON-COMMERCIAL providers. Possible heterogeneity may be due to differences in the work: for example, non-profit organisations (NONCOMMERCIAL providers) provide different jobs than municipalities (PUBLIC providers). Once again it is a priori unclear which types of institutions can be expected to produce better effects. Finally, we evaluate the

\footnotetext{
${ }^{1}$ The studies evaluating vocational training focus on programmes carried out before 1998 .

${ }^{2}$ The effects of JCS with respect to programme heterogeneity have been analysed already in Hujer, Caliendo and Thomsen (2004). We extend these results in three important directions. First, we are able to use regular (unsubsidised) employment as an outcome variable. Second, we extend our observation period until December 2002 making it possible to draw implications about medium-term effects. Third, since we can now use information about the type of support and the institution granting it, we can identify an additional source of potential effect heterogeneity.
} 
effects with respect to the type of support (REGULAR vs. INCREASED support). Given that one aspect of INCREASED support is usually a higher subsidy, it has to be asked whether the effects justify the additional costs. Clearly, all hypotheses can be confirmed or discarded only through empirical examination. Our empirical analysis is based on administrative information of the FEA on all participants who started a JCS in February 2000. Additionally, we have a sample of unemployed persons who were eligible in January 2000 but did not participate in February. The ratio between participants and nonparticipants is approximately 1:20.

It should be noted that although programmes are offered in different economic sectors, substitution between sectors is not possible for potential participants. When the unemployed individual is offered a job in a JCS, this job offer should respond to the unemployed person's individual need for assistance as well as her or his specific level of qualification. For this reason, participation in a JCS in the sector AGRICULTURE, for example, does not necessarily render the individual eligible for a programme in OFFICE AND SERVICES at the same point in time. This mechanism has been confirmed by a number of caseworkers we have interviewed. In addition, caseworkers ensure that potential promoting institutions offer a JCS to the unemployed individuals for whom they are responsible. ${ }^{3}$ Therefore, our analysis differs from studies evaluating the effects of several different labour market programmes (see e.g. Sianesi 2004 for Sweden, Gerfin and Lechner 2002 for Switzerland) in one important respect. Potential participants cannot choose among a set of different programmes, and we have no substitution between the individual programme sectors. Therefore, it is only reasonable to analyse the programme effects in each sector separately in order to draw policy relevant conclusions to improve the design of JCS.

The paper is organised as follows: Section two presents a basic overview of JCS in Germany. In section three, we present the dataset and describe the groups in analysis with additional descriptive results. We outline our evaluation approach and its implementation in the fourth section. In section five we discuss the employment effects of job creation schemes with respect to the programme sectors, types of support and types of providers. The final section concludes.

\section{Some Facts about Job Creation Schemes in Germany}

JCS have been the second most important programme of ALMP in Germany regarding the expenses (3.68 billion euros) and the number of participants (260,079 entries in JCS) at the beginning of our observation period in 2000 (Bundesanstalt für Arbeit 2002a). JCS can be started if they support activities that are of value to so-

\footnotetext{
${ }^{3}$ It has to be noted that the caseworkers interviewed were not selected based on a formal sampling procedure. Instead, we contacted a number of them personally to get more detailed information on the allocation process into JCS in East and West Germany at the local employment agencies.
} 
ciety and additional in nature. ${ }^{4}$ This latter concept means that without the subsidy, the activities would not be executed. For that reason, the majority of JCS is conducted by PUBLIC and NON-COMMERCIAL institutions, although support can also be obtained by private businesses. However, they do have to comply with some special clauses to prevent substitution effects and windfall gains. Besides the social value and the additional benefit of the activities, participants in JCS in the private sector have to be from particular target groups of the labour market, e.g. young unemployed individuals without professional training, and must receive educational supervision as part of the programme. In general, JCS should be offered to individuals for whom participation offers the last chance to stabilise and qualify for later re-integration into regular employment. Hence, JCS are primarily targeted at specific problem groups of the labour market, like long-term unemployed, or persons without work experience or professional training.

Financial support for JCS is obtained as a wage subsidy to the implementing institution. JCS in the PUBLIC sector are accomplished by the administration departments of municipalities and towns, administrative districts, the Federal Authority, churches and universities. NON-COMMERCIAL entities are mainly charities and non-profit organisations. The FEA distinguishes nine different economic sectors for the implementation of programmes, e.g. Agriculture and Construction And Industry. Since the categorisation of the sectors was set up in the mid 1980s, the changes following German reunification and the labour market reforms in the 1990s up to the present have not been taken into account. Thus, several sectors are currently nowadays of only minor importance.

Moreover, two types of support can be distinguished, i.e. REGULAR and INCREASED. INCREASED support is granted for projects which enhance participants' chances for permanent jobs, support structural improvement in social or environmental services or aim at the integration of extremely hard-to-place individuals. In general, JCS should be co-financed measures where between $30 \%$ and $75 \%$ of the costs are subsidies by the FEA and the rest is paid by the provider. The subsidy is normally paid for 12 months. However, exceptions can be made to provide even higher subsidies (up to 100\%), and programme duration can be extended up to 24 or even 36 months, if the JCS create the preconditions for permanent jobs, provide jobs for unemployed individuals with severe labour market disadvantages or improve social infrastructure or environment.

Eligibility for JCS is achieved if persons are either long-term unemployed (more than one year) or unemployed for at least six of the last twelve months. Additionally, they have to be entitled to unemployment compensation. The local placement officers are also allowed to place up to five percent of individuals who do not meet these conditions ('Five-Percent-Quota'). Further exceptions are made for young unemployed (under 25 years) without professional training, short-term unemployed (with at least three months of unemployment)

\footnotetext{
${ }^{4}$ The empirical analysis is based on programmes conducted during 2000 and 2001. As the legal basis has been amended twice (2002/2004), we refer to $\S \S 260-271,416$ of Social Code III before 2002.
} 
placed as tutors, and disabled who could be stabilised or qualified. Up to 2004 by participating in a JCS, particpants' eligibility for unemployment benefits were automatically renewed in the same way as if they were in regular employment.

An important issue to be discussed for the evaluation of the programme effects is how individuals are selected into programmes and programme sectors. In particular, answering the question of why certain unemployed persons participate while others do not is important for modelling the participation decision and the choice of comparison group. The following discussion relies both on evidence from interviews with caseworkers and the institutional settings. Participation in JCS results from placement by the responsible caseworker in the labour office. The unemployed person's efforts in finding a job and the individual's employment probability are evaluated in meetings at regular intervals during the unemployment spell. If the caseworker assesses the unemployed person's situation as requiring assistance through participation in a JCS, he can offer the individual a specific job in one sector if an opening is available. ${ }^{5}$ That is, the particular job offer must relate to the individual's qualifications as assessed by the caseworker in cooperation with the potential participant. Therefore, being offered a job in the sector AGRICULTURE for example, does not imply eligibility for participation in another sector even if a free slot is available at that point of time. Thus, assignment to programmes depends on the assessment of the individual's need of assistance by the local labour office on the one hand, and on the availability of jobs in JCS at that time on the other. However, if an unemployed individual rejects a programme offer one time, the labour office can stop the unemployment benefits for up to twelve months and in the case of repeated rejection, the unemployed person may lose his benefit entitlement altogether. In addition, the responsible caseworker can cancel the programme before completion if the participating individual can be placed in the first labour market.

\section{Dataset, Groups of Analysis and Selected Descriptives}

\subsection{Dataset}

Our dataset is constructed from four administrative sources of the FEA. To describe the individual labour market situation for participants and nonparticipants, we use information from the job-seekers data base (Bewerberangebotsdatei, BewA) and an adjusted version for statistical purposes (ST4). They contain information on all individuals registered at the labour offices as unemployed or facing impending unemployment. The data sources provide each individual's unemployment status information together with important information on the job-seeker's socio-demographic situation, qualification details and labour market history. This information

\footnotetext{
${ }^{5}$ As noted above, caseworkers do also enforce potential promoting institutions to offer specific occupations for the unemployed individuals.
} 
is amended by attributes of subsidised employment programmes (ST11), for example, the economic sector and the programme duration. These three sources constitute a prototype version of the programme participant's master data set (Maßnahme-Teilnehmer-Gesamtdatei, MTG) ${ }^{6}$ For this reason, the MTG contains numerous attributes to describe individual characteristics on the one hand, and provides a reasonable basis for the construction of the comparison group on the other. It should be noted that all information included in the MTG is surveyed by the local caseworkers, i.e. it comprises the set of observable characteristics they use to evaluate the individual's employability as well as some subjective assessments.

As the local labour market environment is an important determinant of programme assignment and impacts, we complete our set of attributes by regional dummies according to the classification of similar and comparable labour office districts by the FEA. This classification categorises the 181 German labour office districts into twelve comparable clusters which can be condensed into five types for strategic purposes. The comparability of the labour office districts is built upon several labour market characteristics. The most important criteria are the underemployment quota and the corrected population density, for further details see Blien et al. (2004). Because all East German labour office districts (except the city of Dresden) belong to the first cluster, we use the finer classification (Clusters Ia, Ib, Ic and II) for the East, whereas for West Germany we rely on the broader one (Clusters II to V). The clusters are ordered according to the labour market prospects starting with the worst labour market environment (Cluster Ia).

For the construction of the outcome variable (regular and unsubsidised employment) we use the Employment Statistics Register (Beschäftigtenstatistik, BSt) as the fourth source of information. The BSt contains information on all persons registered in the social security system (employees and participants of several ALMP programmes). As we define only regular employment as success (all other kinds of subsidised employment or participation in ALMP programmes are defined as failure), we have to identify spells of regular employment without further promotion. To do so, we complete the outcome variable by information of the final version of the MTG that covers information on all periods spent by individuals in ALMP programmes. We are thus able to explicitly identify regular (unsubsidised) employment as the outcome of interest.

Our empirical analysis is based on a cross-section of participants in JCS who started their programmes in February 2000. Since participants and nonparticipants have to be homogeneous in the basic characteristics which determine eligibility to the particular programme under examination, the comparison group is drawn as a random sample of unemployed job-seekers from January 2000. By doing so, we ensured that the nonparticipants were eligible for participation in February 2000, but did not participate in that month. Due to the strongly different situations of the labour market in East and West Germany, we analyse the two regions

\footnotetext{
${ }^{6}$ The final version of the MTG contains information on all ALMP programmes of the FEA, but was not available when our sample was drawn.
} 
separately. Taking into account previous empirical findings (Hujer, Caliendo and Thomsen 2004), we also separate the analysis by gender. Furthermore, we excluded the Berlin local labour market from the analysis: the special situation in the capital city would require a separate evaluation of the effects. However, the small number of participants makes it difficult to draw generalisable conclusions from the results. Our final sample contains 11,151 participants and 219,622 nonparticipants, for whom we observe the employment status up to December 2002, which is almost three years after the programmes started.

\subsection{Groups of Analysis}

Although the FEA distinguishes nine different sectors for the implementation of JCS, there are only four sectors of greater importance: Agriculture, Construction and Industry, OfFice and Services and Community Services. As the sectors Coast Protection and Land Reclamation, Forestry, TRANSPORTATION and SUPPLY FACILITIES are only of minor importance, they are summarised and added to the category OTHER. This leaves us with five sectors for the analysis. Figure 1 presents the number of participants in these sectors in West and East Germany. To allow a reasonable estimation and interpretation of treatment effects, groups with less than 100 participants are excluded from analysis. This is relevant for women in West Germany participating in the sectors AGRICULTURE (41) and CONSTRUCTION AND INDUSTRY (36). Leaving participants in the sector OTHER aside, the majority of men in both regions participate in sectors AgRICULTURE (584 participants in West Germany / 925 in East Germany) and CONSTRUCTION AND INDUSTRY (317/416). The smallest share of male participants is employed in OFFICE AND SERVICES' occupations. On the one hand, this may be due to specific abilities needed for these kind of jobs, which most of the participants may not have. On the other hand, this may also be due to the fact that occupations in this sector tend not to be additional in nature or of value to society. As these are the preconditions for the approval of JCS (see Section 2), this would explain the relatively low share of participants in this sector. The largest share of female participants in both parts can be found in the sector COMMUNITY SERVICES, with 503 participants in West Germany and 1,810 participants in East Germany. In contrast to West Germany, female participants in East Germany are quite often employed in AGRICULTURE. Similar to the West, the smallest group are women in CONSTRUCTION AND INDUSTRY. This first glance already shows significant differences in the allocation to the different sectors, not only between the regions but also between men and women.

Figure 2 further differentiates the number of participants in the different sectors by type of support and provider. Comparing the shares of participants receiving REGULAR and INCREASED support (left-hand side of the figure) shows notable differences between East and West Germany and reflects the worse labour market situation in East Germany. While in West Germany the majority of programmes (over 70\%) is implemented 
Fig. 1: Number of Participants in the Programme Sectors
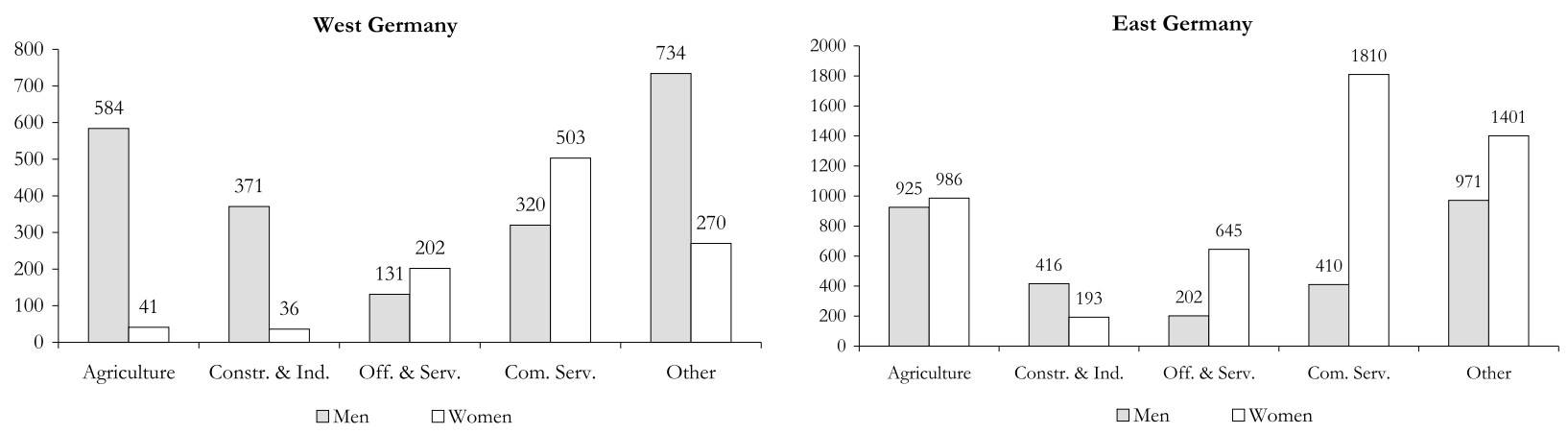

with REGULAR support, in East Germany the picture is inverted. Here, $68 \%$ of the men and $53 \%$ of the women receive INCREASED support. Since one difference between the two types of support among others (see above) is a higher subsidy to the implementing institution, it is not surprising that JCS are on average more expensive in East Germany. While the average monthly cost per participant was 1,419 euros in West Germany in 2001, 1,518 euros were spent on average per participant in East Germany (Bundesanstalt für Arbeit 2002b). The share of REgUlar support is highest in the sectors OfFICE AND SERVICES and Community SERVICES. In West Germany over 96\% of the male participants in the OFFICE AND SERVICES sector receive REGULAR support and $90 \%$ of the women. In COMMUNITY SERVICES the numbers are $69 \%$ for men and $74 \%$ for women. In East Germany the share of participants with REGULAR support is much lower than in West Germany (55\%/62\% of the men/women in OFFICE AND SERVICES, 61\%/60\% in COMMUNITY SERVICES), but still much higher when compared to the other sectors.

The graphs on the right side of Figure 2 present the number of participants differentiated by providers of jobs. Due to the legal requirements of JCS, support of programmes in private businesses is only rarely granted (numbers in brackets). This leads to the fact that the largest group of participants in private businesses are women in the sector OTHER in East Germany (81), and the smallest group are two male participants in the sector OfFICE AND SERVICES in West Germany. Hence, we do not analyse the employment effects of this provider and exclude the respective individuals from analysis.

What becomes obvious from the graphs is that JCS are mainly accomplished by NON-COMMERCIAL entities like charities and non-profit enterprises. Although institutions from the PUBLIC SECTOR, e.g. adminstration departments of municipalities and towns, also provide a substantial number of occupations, they only dominate the schemes in AGRICULTURE for men in West Germany. The dominance of NON-COMMERCIAL ENTITIES is not surprising, since JCS should stabilise and qualify hard-to-place individuals for later reintegration into regular employment by providing temporary occupations that do not compete with regular 
Fig. 2: Number of PARticipants in the Sectors (by tyPe Of SUPPORT AND PROVIDER) a,b
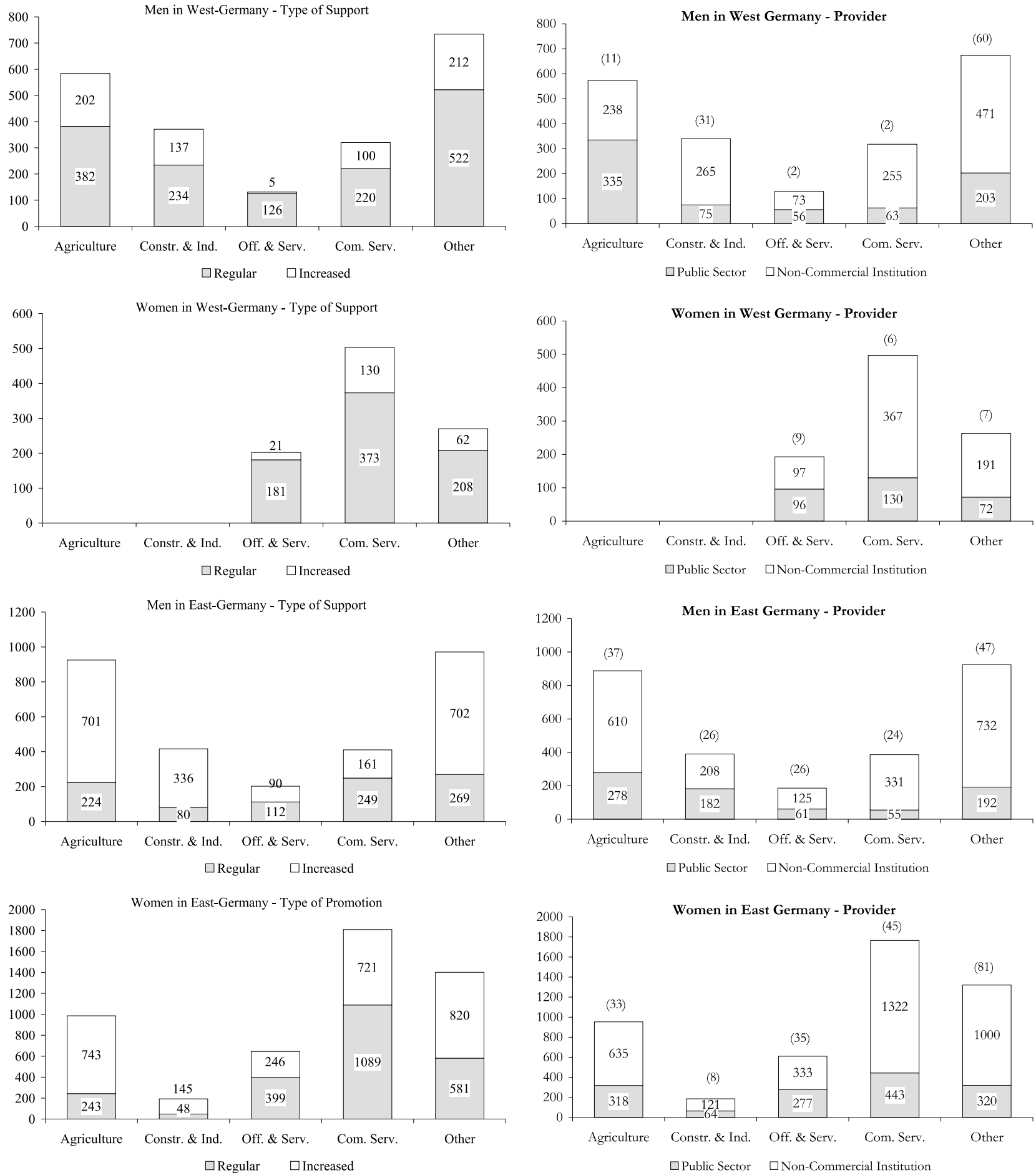

${ }^{a}$ Left side shows the number of participants in the sectors differentiated by type of support (REGULAR and INCREASED).

b Right side shows the number of participants in the sectors differentiated by provider (PUBLIC SECTOR Or NON-COMMERCIAL INSTITUTION, participants in PRIVATE SECTOR in brackets). 
jobs. These regulations are designed to avoid substitution effects and windfall gains and can most likely be met by non-commercial institutions that have a sufficient demand for workers, do not compete with private businesses and could not provide long-run opportunities for comparable employees without the subsidy.

Let us summarise so far: the occupations differ between the sectors and the implementation of schemes differs between the two types of providers. The type of support is heterogeneous and we expect the employment effects to be heterogeneous as well. The direction of this effect heterogeneity is not clear a priori. We have discussed already that the occupations in the different sectors differ and also require different abilities from the participants. However, it is a priori unclear which types of occupation improve the employment chances of individuals most. The same is true regarding the providers and also the third source of possible effect heterogeneity (the type of support), which may have numerous causes. Since one reason for INCREASED support is a greater 'need for assistance', it can be argued that this type should lead to better outcomes, as the costs are usually higher and the programme is more intense. On the other hand, it may also be claimed that those individuals have on average worse labour market prospects. Clearly, these presumptions can be confirmed or discarded only by empirical examination.

\subsection{Selected Descriptives}

Let us briefly consider the different characteristics of participants in the five sectors and compare them with the group of nonparticipants. Tables A.1 to A.4 in the Appendix present means and frequencies of relevant variables differentiated by gender, region and sector. ${ }^{7}$ The attributes are categorised into four types: sociodemographic information, qualification details, labour market history, and regional context. In addition, the average programme duration within the sectors is added. Some notable differences in this data are visible. Whereas men in West Germany experience the shortest programme duration on average in the sector AGRICULTURE with 262 days, their counterparts in this sector in East Germany leave programmes on average after 325 days, i.e. approximately two months later. The small fraction of male participants in OFFICE AND SERVICES participate the longest (337 days in West Germany / 332 in East Germany). Unfortunately, our data lacks information about the reasons for the different durations. We are unable to identify whether programme duration is determined by the planning of the caseworkers at the beginning (nominal duration), or whether better alternatives for the participating individuals are found during the course of the programmes (realised duration). For women in East Germany, the average programme duration differs between sectors, too. The participants in CONSTRUCTION AND INDUSTRY leave the programmes on average after 290 days, whereas women in OTHER stay in programmes for almost 341 days. In contrast, programme durations for women

\footnotetext{
${ }^{7}$ Additional statistics showing means and frequencies of relevant variables further differentiated by implementing institution and type of support are available in the supplementary Appendix (tables C.1 to C.16).
} 
in West Germany vary only minimally. They remain in programmes between 305 days (COMMUNITY SERVICES) and 311 days (ОTHER). Apart from these sectoral differences, it has to be mentioned that participants in West Germany remain in programmes on average for shorter periods compared to those in the East (independently of gender). This may on the one hand be due to better alternatives on the labour market, e.g. regular job opportunities or other ALMP programmes, or on the other hand to a different level of acceptance of the programmes by the participants.

Let us now compare some selected characteristics of participants and nonparticipants in the different sectors. A first point to note is that male nonparticipants in West Germany are, with an average age of 43 years, significantly older than participants (at the end of January 2000). It can also be seen that the age of participants varies considerably between the sectors. Whereas men in CONSTRUCTION AND INDUSTRY and COMMUNITY SERVICES are on average about 35 years old at the begin of programmes, participants in AGRICULTURE are already 39 and in OFFICE AND SERVICES about 43, which almost equals the age of nonparticipants. Looking at the results for women in West Germany shows a similar picture. Again nonparticipants are on average older (43.3 years) than participants, independently of sectors. In contrast, the results for men in East Germany show quite a different picture. Participants are on average clearly older than the nonparticipants. The youngest participants (approximately 43 years old) are employed in COMMUNITY SERVICES and CONSTRUCTION AND INDUSTRY, the oldest in AgRiCUlture (46 years) and OFFICE AND SERVICES (49 years), whereas the nonparticipants are on average 42 years old. Women in East Germany are the most homogeneous group with respect to the ages of participants and nonparticipants. Age varies slightly between 43 years (CONSTRUCTION AND INDUSTRy, Agriculture and Other) and 45 years (OFFICE AND SERVICEs) for participants and is on average 44 years for nonparticipants. Except for women in West Germany, participants in OFFICE AND SERVICES are the oldest in comparison to the other sectors. Although the individual's age may be expected to be an important determinant for a possible re-integration into regular employment and therefore an increasing age should correspond to a longer programme duration, this expectation is only partly confirmed by the data. There is a tendency that programmes last on average longer if participants are older, but no clear pattern can be revealed. With respect to health restrictions, we find that men without health restrictions are overrepresented in the sectors AGRICULTURE and CONSTRUCTION AND INDUSTRY when compared to nonparticipants. This is intuitively understandable since occupations in these sectors may involve some form of manual labour.

It is quite interesting to look at the professional training of individuals in the different sectors. Participants without completed professional training are overrepresented in the sectors AGRICULTURE and CONSTRUCTION AND INDUSTRY, whereas individuals with higher degrees are overrepresented in the sectors OFFICE And Services and Community Services. Both points are true irrespective of gender and region, even though the first point is less pronounced in East Germany. This is due to the fact that most of the individuals 
in East Germany have at least some formal degree ('industrial training'). Clearly, this has also to be seen in relation to the higher age of participants in East Germany. The professional rank points in the same direction. Men in West Germany who are white-collar workers are overrepresented in the OFFICE AND SERVICES sector and unskilled workers are primarily found in AGRICULTURE or CONSTRUCTION AND INDUSTRY. Whitecollar females in West Germany are remarkably overrepresented in OFFICE AND SERVICES and COMMUNITY SERVICES. Taken together, these findings indicate that more highly qualified persons are more likely to be found in the sectors OFFICE AND SERVICES and COMMUNity SERVICES, whereas low-qualified individuals are more likely to be in Agriculture or CONSTRUCTION AND INDUSTRY. A last point to note is that nonparticipants in West Germany have on average more work experience when compared to the participants. In East Germany, the situation is much more balanced and no large differences in work experience between participants and nonparticipants are visible.

These findings confirm two expectations. First, participants and nonparticipants differ remarkably in their characteristics. Clearly, this is to be expected and highlights that a simple comparison of treated and nontreated individuals will lead to selection bias. We will address this problem in the next section. Second, participants in the different economic sectors of JCS also have rather different characteristics, and the estimation has to take this into account properly.

\section{Evaluation Approach}

\subsection{Matching Estimator}

Our empirical analysis is based on the standard framework in the microeconometric evaluation literature, the so-called potential outcome approach (see Roy 1951 and Rubin 1974). In this framework an individual can choose between two states, e.g. participating in a certain labour market programme or not. For each individual, there are two potential outcomes, where $Y^{1}$ denotes the outcome with treatment and $Y^{0}$ is the outcome without treatment. The actually observed outcome for any individual $i$ is given by: $Y_{i}=Y_{i}^{1} \cdot D_{i}+\left(1-D_{i}\right) \cdot Y_{i}^{0}$, where $D \in\{0,1\}$ is a binary treatment indicator. The treatment effect for each individual $i$ is defined as the difference between the potential outcomes, i.e. $\Delta_{i}=Y_{i}^{1}-Y_{i}^{0}$. Imbens (2000) and Lechner (2001) generalise this approach for situations where a whole range of treatments is available. Although JCS comprise activities in very different economic sectors, the discussion in section 2 has shown that potential participants are exposed to a specific job in one sector only. Therefore, we do not need to consider the effects of a programme in one sector relative to another, but only in comparison to nonparticipation. ${ }^{8}$ Hence, we can restrict our description

\footnotetext{
${ }^{8}$ The description of the allocation mechanism above has shown that unemployed individuals do not have an opportunity to choose between different jobs in JCS since occupations are offered in line with the qualification and needs of the individual.
} 
to the binary case.

The parameter of interest is the average effect of treatment on the treated (ATT), defined as:

$$
A T T=E(\Delta \mid D=1)=E\left(Y^{1} \mid D=1\right)-E\left(Y^{0} \mid D=1\right) .
$$

Since the second term on the right-hand side is unobservable (it describes the hypothetical outcome without treatment for those individuals who received the treatment), Eq. (1) is not identified and additional assumptions are needed. As we work with non-experimental data, we cannot simply take the nonparticipants' outcome $E\left(Y^{0} \mid D=0\right)$ as an approximation of the participants' outcome had they not participated. This would lead to selection bias, since participants and nonparticipants are selected groups that would have different outcomes even in the absence of treatment. However, if we are able to observe all determinants that jointly influence the participation decision and the labour market outcomes, differences in the observable attributes between participating and nonparticipating individuals can be adjusted away. Then, treatment decision and treatment outcomes become independent conditional on a set of covariates $X$. This is the so-called conditional independence assumption (CIA): $Y^{0} \amalg D \mid X$, where $\amalg$ denotes independence. ${ }^{9}$

Given that the CIA holds and that we have access to a large group of eligible nonparticipants, the matching estimator is an appealing choice. Its basic idea is to find for each participant one nonparticipant which is similar in all relevant (observable) characteristics $X$. It is well known that matching on $X$ can become impossible when $X$ is of high dimension ('curse of dimensionality'). To deal with this dimensionality problem, Rosenbaum and Rubin (1983) suggest the use of balancing scores. For participants and nonparticipants with the same balancing score, the distributions of the covariates $X$ are the same, i.e. they are balanced across the groups. The propensity score $P(X)$, i.e. the probability of participating in a programme is one possible balancing score, which summarises the information of the observed covariates $X$ into a single index function. Rosenbaum and Rubin (1983) show that if treatment assignment is strongly ignorable given $X$, it is also strongly ignorable given any balancing score. Hence, it is sufficient to assume that: $Y^{0} \amalg D \mid P(X)$. In order to find comparable non-treated individuals for all treated observations it is usually additionally assumed that $\operatorname{Pr}(D=1 \mid X)<1$, for all $X$. Several matching procedures have been suggested in the literature. ${ }^{10}$ We tested the sensitivity of the estimates with respect to the algorithm choice (see Caliendo, Hujer and Thomsen 2005). It turns out that the results are not sensitive to this choice for our dataset and that nearest-neighbour $(\mathrm{NN})$ matching with an additional calliper of 0.02 is the most favourable choice. ${ }^{11}$ Given the large sample of nonparticipants, we additionally match 'without replacement'.

\footnotetext{
${ }^{9}$ It should be noted that we only require the nonparticipating outcome to be independent of the participation decision conditional on $X$ to estimate ATT.

${ }^{10}$ Good overviews can be found in Heckman, Ichimura, Smith and Todd (1998), Smith and Todd (2005) and Imbens (2004). For calliper matching see Cochran and Rubin (1973).

${ }^{11}$ Matching has been implemented using the Stata module psmatch2 by Leuven and Sianesi (2003).
} 


\subsection{Plausibility of the CIA and Comparison Group}

Clearly, the CIA is in general a very strong assumption and the applicability of the matching estimator depends crucially on the plausibility of the CIA. Hence, we will discuss and justify the plausibility of the CIA in our context in this section. Blundell, Dearden and Sianesi (2004) argue that the plausibility of such an assumption should always be discussed on a case-by-case basis, thereby taking account of the informational richness of the data. Implementation of matching estimators requires choosing a set of variables that credibly justify the CIA. Only variables that simultaneously influence the participation decision and the outcome variable should be included in the matching procedure. Hence, economic theory, a sound knowledge of previous research and also information about the institutional settings should guide the researcher in specifying the model (see e.g. Smith and Todd 2005 or Sianesi 2004). Both economic theory and previous empirical findings highlight the importance of socio-demographic and qualificational variables. Regarding the first category we can use variables such as age, marital status, number of children, nationality (German or foreigner) and health restrictions. The second class (qualification variables) refers to the human capital of the individual which is also a crucially important determinant of labour market prospects. The attributes available are professional training, occupational group, professional rank, and work experience of the individual. Furthermore, as pointed out by Heckman and Smith (1999), unemployment dynamics and the labour market history play a major role in driving outcomes and programme participation. Hence, we use career variables describing the individual's labour market history, such as the duration of the last employment, the duration of unemployment at the end of January 2000, the number of (unsuccessful) placement propositions, the last contact to the job center and whether the individual plans to take part in vocational rehabilitation or has already participated in a programme before. Heckman, Ichimura, Smith and Todd (1998) additionally emphasise the importance of drawing treated and comparison people from the same local labour market and giving them the same questionnaire. Since we use administrative data from the same sources for participants and nonparticipants, the latter point is a given in our analysis. To account for the local labour market situation we use the regional context variables described above.

Finally, the institutional structure and the selection process into JCS provide some further guidance in selecting the relevant variables. As we have seen from the discussion in Section 2, JCS are in general open to all job-seekers who meet the eligibility criteria. However, what should have become clear is that participation in programmes depends on the individual's need for assistance as evaluated by the responsible caseworker and on the availability of a free slot in the particular sector that fits the individual's characteristics. Caseworkers assess the individual's need for assistance based on the set of socio-demographic, qualificational, and career variables used in our analysis. In addition, we are able to use the caseworkers' subjective assessments of the 
individuals' placement restrictions as well. Based on the overall very informative dataset, we argue henceforth that the CIA holds in our setting. ${ }^{12}$

Choosing a proper comparison group is the next thing to do. Although participation in ALMP programmes is not mandatory in Germany, the majority of unemployed persons join a programme after some time. Thus, comparing participants to individuals who will never participate is inadequate, since it can be assumed that the latter group is particularly selective. ${ }^{13}$ Sianesi (2004) discusses this problem for Sweden and argues that these persons are the ones who do not enter a programme because they have already found a job. Therefore, we restrict our comparison group to those who are unemployed and eligible at the end of January 2000 and not participating in February 2000 (but may possibly join a programme later). ${ }^{14}$ The ratio of participants to nonparticipants in February 2000 in our data is 1:20.

\subsection{Propensity Score Estimation}

As we want to evaluate the impacts of participation in JCS in a specific economic sector, with a specific type of support, and with respect to the implementing institution, we have to take account of differences regarding the assignment to programmes. For example, it has become obvious from the findings in Section 3.3 that more highly qualified individuals are more likely to be found in the sectors OFFICE AND SERVICES and COMMUNITY SERVICES, whereas lower-qualified ones are more likely to be in AGRICULTURE or CONSTRUCTION AND INDUSTRY. Hence, it can be expected that the attribute 'professional training' has a different influence on the participation probability in the different sectors. Thus, we estimate the propensity scores separately for every treatment group in analysis against the group of nonparticipants. To do so, we use binary logit models. ${ }^{15}$ To abbreviate documentation of the propensity score estimations, we only discuss the results for the five sectors in the following. ${ }^{16}$

The results for the propensity score estimations for the five sectors can be found in Tables A.5 (Men) and A.6 (Women) for West Germany as well as in Tables A.7 (Men) and A.8 (Women) for East Germany in the appendix. We see immediately that the parameters of the choice estimations differ not only with respect

\footnotetext{
${ }^{12}$ In Caliendo, Hujer and Thomsen (2005) we have also tested the sensitivity of the results to unobserved heterogeneity. The results turned out to be robust, indicating that the data used is in fact informative enough to base the analysis on the CIA.

${ }^{13}$ Furthermore, it should be noted that using individuals who are observed to never participate in the programmes as the comparison group may invalidate the conditional independence assumption due to a conditioning on future outcomes (see the discussion in Fredriksson and Johansson (2004)).

${ }^{14}$ Tables C.21 and C.22 in the supplementary Appendix provide information on the labour market destinations during the observation period of the nonparticipating individuals in February 2000. It becomes obvious that during the observation period only a minor part of these individuals participate in ALMP programmes (about 4.5\% (3.4\%) of the male (female) nonparticipants in West Germany and about $8.3 \%$ (7.8\%) in East Germany in December 2002).

${ }^{15}$ As we exclude groups of less than 100 participating individuals, we estimate 18 logit models for the five sectors, 29 logit models for the five sectors with respect to the type of support, and 26 logit models for the five sectors with respect to the type of provider. For all groups in consideration we estimate the models with respect to region and gender separately.

${ }^{16}$ The results of the estimations for the other groups (type of support, type of provider) are available on request by the authors.
} 
to regional and gender-specific differences, but also with respect to sector-specific aspects. Clearly, this has been expected based on the descriptive analysis. For example, married men (0.6680) and women (0.1677) in East Germany have a higher probability to join a programme in the sector COMMUNITY SERVICES than men $(-0.2582$ / insignificant) and women (-0.4877) in the West. A good example of sector-specific differences is the individuals' age. Whereas age has a negative impact on the probability for men in West Germany to join CONSTRUCTION AND INDUSTRY (-0.1343), it has a positive effect for them to join OFFICE AND SERVICES (0.3791). Clearly, there are also variables that influence participation probabilities irrespective of gender and region. For example, the number of placement propositions increases the participation probabilities for men and women in both parts and all sectors. Moreover, there is a strong tendency for men and women with health restrictions to participate in the sectors OfFICE AND SERVICES or COMMUNiTy SERVICES when compared to individuals without health restrictions. This makes sense, as it is not very likely for people with health problems to work in the sectors AGRICUlture or CONSTRUCTION AND INDUSTRY. People with higher qualifications tend to go into the sectors OFFICE AND SERVICES and COMMUNITY SERVICES, too. For example the coefficient for West German men with a college or university degree to join the sector OFFICE AND SERVICES is 1.5608 , whereas this characteristic reduces the probability to join AGRICULTURE $(-1.2767)$. The influence of professional rank works in the same direction. Individuals with a higher rank (compared to unskilled workers) are less likely to participate in AGRICULTURE (and to a certain extent also CONSTRUCTION AND INDUSTRY). The coefficients for the occupational groups are as expected. People who come from service professions are also more likely to join sectors OFFICE AND SERVICES and COMMUNITY SERVICES and less likely to join AgRiCULTURE and CONSTRUCTION AND INDUSTRY. No clear differences between the sectors can be found for the unemployment duration and the duration of last employment. The latter one decreases the participation probability for all groups in all sectors. The unemployment duration considered in three classes: less than 13 weeks (reference), 13 to 52 weeks and over 52 weeks - has significant influence mainly in East Germany, where it increases the probability for nearly all sectors. Overall, it can be stated that sector-specific differences play a major role in the participation probabilities.

\subsection{Matching Quality and Common Support}

Based upon the propensity score estimates and the chosen matching algorithm, we check the matching quality by comparing the standardised bias (SB) before and after matching. Since we do not condition on all the covariates but on the propensity scores, this is a necessary step to see if the matching procedure is able to balance the distribution of the covariates between the group of participants and nonparticipants. ${ }^{17}$ The SB,

\footnotetext{
${ }^{17}$ See Caliendo and Kopeinig (2005) for an exhaustive discussion on how to test matching quality and common support.
} 
as suggested by Rosenbaum and Rubin (1985), assesses the distance in the marginal distributions of the $X$-variables. For each covariate $X$, it is defined as the difference of the sample means in the treated and (matched) comparison sub-samples as a percentage of the square root of the average of the sample variances in both groups. The SB before and after matching is given by:

$$
S B=100 \cdot \frac{\left(\bar{X}_{1 t}-\bar{X}_{0 t}\right)}{\sqrt{0.5 \cdot\left(V_{1 t}(X)+V_{0 t}(X)\right)}}, \text { with } t \in(0,1) .
$$

$X_{1}\left(V_{1}\right)$ is the mean (variance) in the treated group and $X_{0}\left(V_{0}\right)$ the analogue for the comparison group before matching if $t=0$, and the corresponding values after matching if $t=1$. For the sake of brevity, we calculated the means of the SB before and after matching for men and women in West and East Germany for the different treatments in consideration as an unweighted average of all variables (mean standardised bias, MSB). The results can be found in Table 1.

Starting with the results for the five sectors, for men in West Germany we see that the overall bias before matching is between $14.77 \%$ (OTHER) and $23.23 \%$ (OFFICE AND SERVICES). The matching procedure is able to achieve a significant reduction in all of the sectors and leads to a MSB after matching between 3.42\% and $4.33 \%$ for four of the five sectors. ${ }^{18}$ The MSB after matching in the sector OFFICE AND SERVICES is still quite high (6.86\%). But taking into account that this is the smallest group of men in West Germany and that it was reduced in size dramatically after matching, this is acceptable. For women in West Germany, the MSB is reduced from $21.76 \%$ to $5.31 \%$ in the sector OFFICE AND SERVICES, from $18.11 \%$ to $3.07 \%$ in the sector COMMUNITY SERVICES and from $15.83 \%$ to $5.01 \%$ in the sector OTHER. In East Germany the bias reduction is even better, leaving us with a MSB after matching between 2.17\% (AGRICULTURE) and 5.72\% (OFFICE AND SERVICES) for men and between 1.58\% (COMMUNITy SERVICES) and 5.74\% (CONSTRUCTION AND INDUSTRY) for women. Overall, these are enormous reductions and show that the matching procedure is able to balance the characteristics in the treatment and the matched comparison group.

Also for the further groups differentiated by type of support and implementing institution, the propensity score specification is able to reduce the MSB after matching for most groups. However, there are some groups for which the MSB after matching is still quite high. For example, women receiving increased support in the sector COMmunity SERVICES in West Germany have a MSB after matching of 10.48\%. This highlights the fact that it is not always possible to find comparable individuals in the group of nonparticipants and that the

\footnotetext{
${ }^{18}$ Additionally, we have included the standardised bias before and after matching for each variable in the main groups in tables C. 17 to C.20 in the supplementary appendix. Looking at those more detailed results shows that the matching procedure increases the bias for a few variables. These are in particular categorial dummy variables. For example when looking at men participating in the AGRICULTURE sector in West Germany (table C.17), the SB in the variable 'professional rank' rises for the category 'other professional rank' from $4.55 \%$ before matching to $4.82 \%$ after matching. However, this increase has to be seen in relation to the high decrease in the other categories of this variable, e.g. the bias for 'unskilled workers' drops from $43.66 \%$ to $5.16 \%$. Hence, it is only of minor importance.
} 
Tab. 1: Mean Standardised Bias Before and After Matching in PROGRAMME SECTORS ${ }^{1}$

\begin{tabular}{|c|c|c|c|c|c|c|c|c|c|c|}
\hline & \multirow{2}{*}{\multicolumn{2}{|c|}{$\begin{array}{c}\text { All } \\
\text { Individuals }\end{array}$}} & \multicolumn{4}{|c|}{ Support } & \multicolumn{4}{|c|}{ Provider } \\
\hline & & & \multicolumn{2}{|c|}{ REGULAR } & \multicolumn{2}{|c|}{ INCREASED } & \multicolumn{2}{|c|}{ PUBLIC } & \multicolumn{2}{|c|}{ NON-COMM. } \\
\hline & before & after & before & after & before & after & before & after & before & after \\
\hline \multirow{2}{*}{\multicolumn{11}{|c|}{$\begin{array}{l}\text { West Germany } \\
\text { Men }\end{array}$}} \\
\hline & & & & & & & & & & \\
\hline Agriculture & 18.88 & 3.76 & 19.56 & 4.33 & 19.81 & 5.88 & 19.07 & 5.08 & 18.79 & 5.97 \\
\hline Construction \& Industry & 22.32 & 3.70 & 19.16 & 5.62 & 26.81 & 5.61 & - & - & 21.18 & 4.62 \\
\hline Office \& Services & 23.23 & 6.86 & 23.10 & 7.01 & - & - & - & - & - & - \\
\hline Community Services & 17.89 & 4.33 & 16.86 & 6.10 & - & - & - & - & 17.47 & 5.65 \\
\hline Other & 14.77 & 3.42 & 14.82 & 3.16 & 20.67 & 6.29 & 19.05 & 5.25 & 15.08 & 3.48 \\
\hline \multicolumn{11}{|l|}{ Women } \\
\hline Agriculture & - & - & - & - & - & - & - & - & - & - \\
\hline Construction \& Industry & - & - & - & - & - & - & - & - & - & - \\
\hline Office \& Services & 21.76 & 5.31 & 22.01 & 6.07 & - & - & - & - & - & - \\
\hline Community Services & 18.11 & 3.07 & 18.34 & 3.43 & 22.65 & 10.48 & 19.49 & 7.69 & 18.28 & 3.97 \\
\hline Other & 15.83 & 5.01 & 16.63 & 3.81 & - & - & - & - & 15.40 & 5.52 \\
\hline \multirow{2}{*}{\multicolumn{11}{|c|}{$\begin{array}{l}\text { East Germany } \\
\text { Men }\end{array}$}} \\
\hline & & & & & & & & & & \\
\hline Agriculture & 17.02 & 2.17 & 17.53 & 5.23 & 17.46 & 3.18 & 17.53 & 5.80 & 16.86 & 3.26 \\
\hline Construction \& Industry & 16.65 & 4.02 & - & - & 15.73 & 3.76 & 18.11 & 7.98 & 16.20 & 5.74 \\
\hline Office \& Services & 25.43 & 5.72 & 27.60 & 7.93 & - & - & - & - & 26.19 & 7.52 \\
\hline Community Services & 16.24 & 4.13 & 18.29 & 3.76 & 17.30 & 5.17 & - & - & 16.36 & 4.97 \\
\hline Other & 11.55 & 3.05 & 17.11 & 4.01 & 11.54 & 3.74 & 13.44 & 6.15 & 11.44 & 3.52 \\
\hline \multicolumn{11}{|l|}{ Women } \\
\hline Agriculture & 18.10 & 2.14 & 16.95 & 5.23 & 17.92 & 2.92 & 17.45 & 5.27 & 18.25 & 3.02 \\
\hline Construction \& Industry & 13.11 & 5.74 & - & - & 14.17 & 6.10 & - & - & 14.66 & 8.25 \\
\hline Office \& Services & 17.62 & 3.02 & 18.18 & 9.94 & 17.13 & 4.70 & 18.13 & 9.47 & 17.50 & 4.10 \\
\hline Community Services & 11.81 & 1.58 & 13.46 & 2.37 & 10.77 & 3.20 & 13.86 & 3.83 & 11.58 & 2.05 \\
\hline Other & 11.03 & 2.73 & 13.11 & 3.68 & 12.05 & 2.75 & 13.77 & 3.87 & 10.87 & 3.31 \\
\hline
\end{tabular}

matching approach is limited in such situations. Fortunately, this is only the case for very few of the groups in analysis, but has to be considered when interpreting the results.

A final aspect to bear in mind when implementing matching is the region of common support between participants and nonparticipants. Clearly, matching estimates are only identified in the common support region and treated individuals who fall outside this region have to be discarded. If the share of individuals lost is high, the effects have to be re-interpreted, which might cause problems for the explanatory power of the results. Table A.9 in the Appendix shows the number of lost treated individuals due to missing common support. For men in West Germany, we lose between zero (CONSTRUCTION AND INDUSTRY) and 1.53\% (OFFICE AND SERVICES) of all treated individuals, which corresponds to a total loss of ten participants. For women in West Germany, we lose seven observations and the numbers in East Germany are even lower with four men and five women. The picture is equally good for the further groups defined by different providers and types of support. ${ }^{19}$ Hence, common support is guaranteed and not a problem for this analysis.

\footnotetext{
${ }^{19}$ One exception are women in West Germany participating in COMMUNITY SERVICES receiving INCREASED support. For this group we lose $14.6 \%$ of the observations. This corresponds to the finding regarding the MSB in this group and basically permits a further interpretation of the results in this group.
} 


\section{Sectoral Employment Effects}

\subsection{Gender and Regions}

Let us start our discussion of the employment effects with the different programme sectors. The estimated treatment effects, i.e. the differences in the employment rates between participants and matched nonparticipants, are depicted in Table 2. To allow a more accurate discussion, we present the results for six selected months only. In addition, Figures 3 and 4 contain the plots of the treatment effects over time from February 2000 to December 2002.

A first obvious finding that is common to all groups is a clear decrease in the effects shortly after programmes have started. This development is not surprising, since participants in JCS only have limited opportunities (and incentives) to look for regular employment whilst in the programme ('locking-in effects). In contrast, nonparticipants continue to search and apply for new jobs with higher intensity. However, it should be noted that these locking-in effects vary considerably not only between the different sectors, but also between the two regions. To give an example, five months after programmes have started (July 2000), we find significant negative employment effects for men in West Germany that range from -15.6 (AGRICULTURE) over -23.2 (CONSTRUCTION AND INDUSTRY) to -27.2 percentage points (COMMUNITY SERVICES). This means that the average employment rate for male participants in the sector COMMUNITY SERVICES is 27.2 percentage points lower compared to matched nonparticipants.

Looking at the characteristics of the participants in the different sectors might help to shed some light on these large differences. The descriptive results (see Table A.1 in the Appendix) have shown that about 45\% of the participating men in West Germany in the sector AGRICULTURE are unskilled workers. Additionally, about $70 \%$ lack professional training. Taking the same figures for participants in CONSTRUCTION AND INDUSTRY shows that the share of persons without professional training is larger (75\%), whereas the share of unskilled individuals is smaller (39\%). However, if we compare these findings with the participants in the sector COMMUNiTy SERVICES, where we observe the strongest locking-in effects, we see that here the number of unskilled individuals (18\%) as well as the number of persons who lack professional training (52\%) are clearly lower. Hence, the differences can (to some extent) be explained by the characteristics of individuals allocated to the different sectors. The matched nonparticipants in the sector AGRICULTURE are less qualified and therefore have only limited labour market chances. Therefore, participants in AGRICULTURE experience lower locking-in effects when compared to other sectors, such as COMMUNITY SERVICES, where the matched nonparticipants have on average better labour market characteristics. However, although participants in JCS in CONSTRUCTION AND INDUSTRY have similar characteristics to the participants in AgRICUlture, they experience clearly stronger locking-in effects whilst in the programmes, which might be due to seasonal ef- 
Tab. 2: Sectoral Employment Effects for Selected Months ${ }^{1}$

\begin{tabular}{|c|c|c|c|c|c|c|c|}
\hline \multicolumn{8}{|l|}{$\begin{array}{l}\text { West Germany } \\
\text { Men }\end{array}$} \\
\hline & & Jul 00 & Dec 00 & Jul 01 & Dec 01 & Jul 02 & Dec 02 \\
\hline \multirow{2}{*}{ AgRICULTURE } & Effect & -0.1561 & -0.0892 & -0.0772 & -0.0223 & -0.0309 & 0.0086 \\
\hline & S.E. & 0.0160 & 0.0166 & 0.0202 & 0.0245 & 0.0268 & 0.0256 \\
\hline \multirow{2}{*}{ CONSTRUCTION AND INDUSTRY } & Effect & -0.2318 & -0.1833 & -0.1321 & -0.0108 & 0.0000 & 0.0243 \\
\hline & S.E. & 0.0204 & 0.0232 & 0.0300 & 0.0338 & 0.0360 & 0.0330 \\
\hline \multirow{2}{*}{ OFFICE AND SERVICES } & Effect & -0.2016 & -0.2016 & -0.1550 & -0.0853 & 0.0930 & 0.1008 \\
\hline & S.E. & 0.0323 & 0.0315 & 0.0384 & 0.0384 & 0.0465 & 0.0486 \\
\hline \multirow{2}{*}{ COMmunity SERVICES } & Effect & -0.2722 & -0.2057 & -0.1203 & -0.0886 & -0.0190 & -0.0032 \\
\hline & S.E. & 0.0317 & 0.0299 & 0.0333 & 0.0332 & 0.0314 & 0.0334 \\
\hline \multirow{2}{*}{ OTHER } & Effect & -0.1956 & -0.1669 & -0.1094 & -0.0725 & -0.0027 & 0.0027 \\
\hline & S.E. & 0.0163 & 0.0187 & 0.0232 & 0.0236 & 0.0246 & 0.0235 \\
\hline \multicolumn{8}{|l|}{ Women } \\
\hline \multirow{2}{*}{ AGRICULTURE } & Effect & - & - & - & - & - & - \\
\hline & S.E. & - & - & - & - & - & - \\
\hline \multirow{2}{*}{ CONSTRUCTION AND INDUSTRY } & Effect & - & - & - & - & - & - \\
\hline & S.E. & - & - & - & - & - & - \\
\hline \multirow{2}{*}{ OFFICE AND SERVICES } & Effect & -0.2289 & -0.2438 & -0.1144 & -0.0647 & 0.0498 & 0.0796 \\
\hline & S.E. & 0.0289 & 0.0333 & 0.0480 & 0.0434 & 0.0448 & 0.0482 \\
\hline \multirow{2}{*}{ COMMUNity SERVICES } & Effect & -0.1932 & -0.2173 & -0.1127 & -0.0865 & -0.0020 & 0.0362 \\
\hline & S.E. & 0.0171 & 0.0234 & 0.0270 & 0.0283 & 0.0315 & 0.0273 \\
\hline \multirow{2}{*}{ OTHER } & Effect & -0.2000 & -0.2185 & -0.1296 & -0.0926 & -0.0037 & 0.0444 \\
\hline & S.E. & 0.0249 & 0.0292 & 0.0337 & 0.0391 & 0.0423 & 0.0447 \\
\hline \multicolumn{8}{|l|}{$\begin{array}{l}\text { East Germany } \\
\text { Men }\end{array}$} \\
\hline \multirow{2}{*}{ AGRICULTURE } & Effect & -0.1427 & -0.0984 & -0.1146 & -0.0605 & -0.0714 & -0.0216 \\
\hline & S.E. & 0.0123 & 0.0124 & 0.0140 & 0.0148 & 0.0161 & 0.0148 \\
\hline \multirow{2}{*}{ CONSTRUCTION AND INDUSTRY } & Effect & -0.1947 & -0.1370 & -0.1298 & -0.0769 & -0.0841 & -0.0601 \\
\hline & S.E. & 0.0173 & 0.0230 & 0.0237 & 0.0244 & 0.0217 & 0.0238 \\
\hline \multirow{2}{*}{ OFFICE AND SERVICES } & Effect & -0.1343 & -0.1343 & -0.1144 & -0.0746 & -0.0249 & 0.0199 \\
\hline & S.E. & 0.0181 & 0.0240 & 0.0334 & 0.0343 & 0.0378 & 0.0360 \\
\hline \multirow{2}{*}{ COMMUNITY SERVICES } & Effect & -0.1327 & -0.1425 & -0.1376 & -0.0860 & -0.0467 & -0.0319 \\
\hline & S.E. & 0.0218 & 0.0185 & 0.0255 & 0.0253 & 0.0279 & 0.0203 \\
\hline \multirow{2}{*}{ OTHER } & Effect & -0.1401 & -0.1205 & -0.0989 & -0.0639 & -0.0649 & -0.0340 \\
\hline & S.E. & 0.0105 & 0.0113 & 0.0139 & 0.0138 & 0.0149 & 0.0164 \\
\hline \multicolumn{8}{|l|}{ Women } \\
\hline \multirow{2}{*}{ AgRICULTURE } & Effect & -0.0873 & $\begin{array}{c}-0.0782 \\
\end{array}$ & $\begin{array}{c}-0.0711 \\
\end{array}$ & -0.0650 & -0.0376 & -0.0183 \\
\hline & S.E. & 0.0084 & 0.0094 & 0.0125 & 0.0126 & 0.0121 & 0.0144 \\
\hline \multirow{2}{*}{ CONSTRUCTION AND INDUSTRY } & Effect & -0.1295 & -0.0984 & -0.1036 & -0.0207 & -0.0415 & 0.0104 \\
\hline & S.E. & 0.0233 & 0.0229 & 0.0310 & 0.0286 & 0.0320 & 0.0311 \\
\hline \multirow{2}{*}{ OFFICE AND SERVICES } & Effect & -0.0916 & -0.0916 & -0.0652 & -0.0807 & -0.0575 & -0.0497 \\
\hline & S.E. & 0.0102 & 0.0106 & 0.0174 & 0.0173 & 0.0184 & 0.0174 \\
\hline \multirow{2}{*}{ COMmunity SERvices } & Effect & -0.0867 & -0.0912 & -0.0602 & -0.0343 & -0.0133 & 0.0232 \\
\hline & S.E. & 0.0063 & 0.0075 & 0.0107 & 0.0118 & 0.0126 & 0.0111 \\
\hline OTHER & Effect & -0.1001 & -0.1023 & -0.0851 & -0.0601 & -0.0572 & -0.0258 \\
\hline & S.E. & 0.0087 & 0.0066 & 0.0105 & 0.0105 & 0.0111 & 0.0131 \\
\hline
\end{tabular}

Bold letters indicate significance on a $1 \%$ level, italic letters refer to the $5 \%$ level, standard errors are bootstrapped with 50 replications.

Results refer to NN matching without replacement and a caliper of 0.02 .

${ }^{1}$ Groups of less than 100 participants are excluded from estimation.

fects. Since our analysis starts in February, matched nonparticipants in the construction sector are more likely to find employment during spring and summer, independent of their qualifications. Similar to the results for men, women in West Germany experience large locking-in effects as well. In July 2000 we find negative employment effects ranging from -19.3 (COMMUNITY SERVICES) to -22.9 percentage points (OFFICE AND SERVICES). 
Fig. 3: Sectoral Employment EfFects in West Germany (February 2000 - DECEMBER 2002) $)^{1,2,3}$
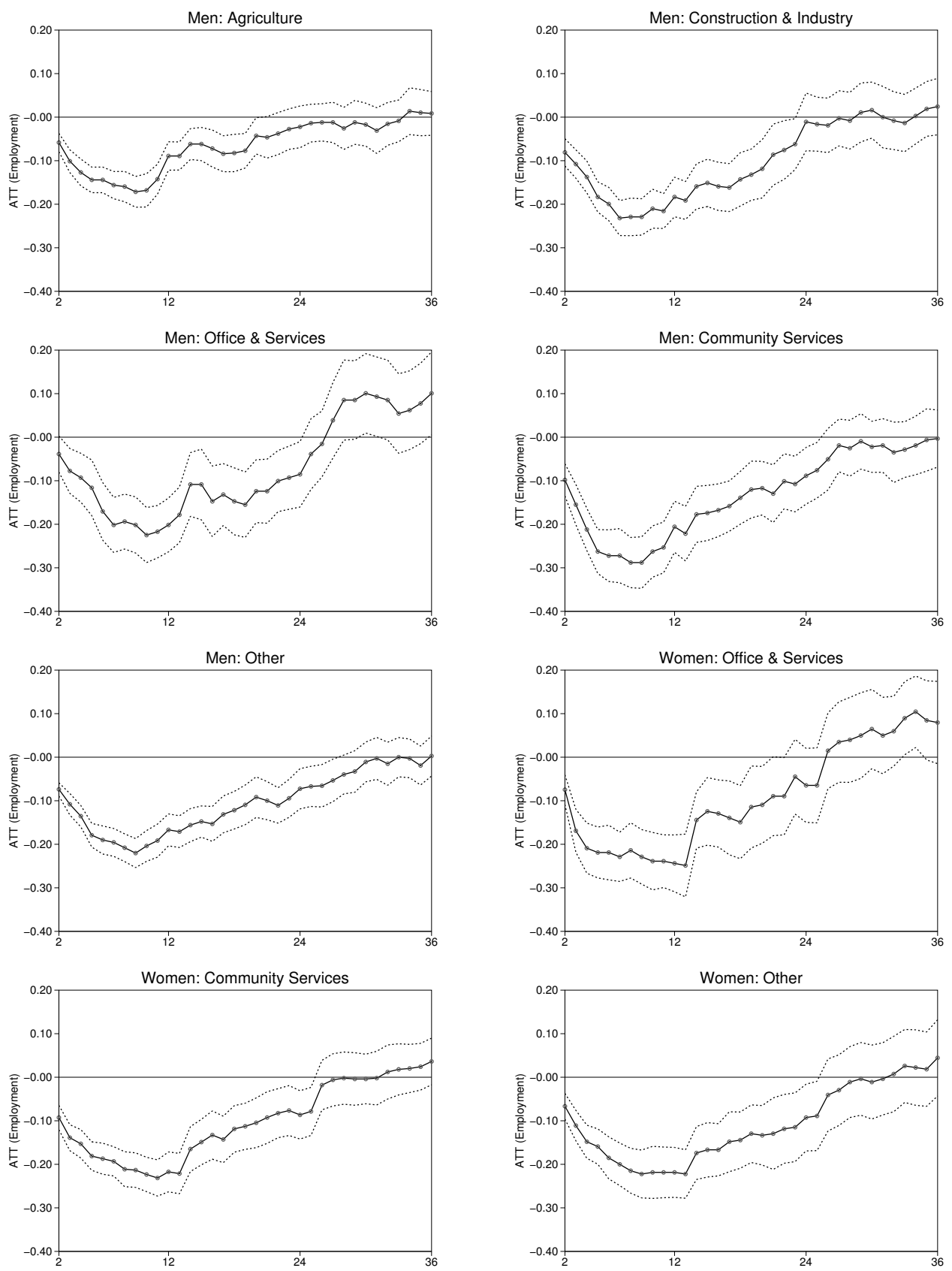

${ }^{1}$ Solid line describes the monthly employment effect. Dotted lines are the upper and lower $95 \%$ confidence limits.

2 Month 2 refers to February 2000, month $12=$ December 2000, month $24=$ December 2001, month $36=$ December 2002.

3 Effects for groups with less than 100 participants are omitted.

The locking-in effects in East Germany are less pronounced. For men in East Germany, the effects are bounded between -13.3 (COMmunity SERvices) and -14.3 percentage points (AgRICUlTURE). One exception are men in CONSTRUCTION AND INDUSTRY, who experience a negative employment effect of -19.5 percentage points in July 2000. Whereas the strong decrease for participants in CONSTRUCTION AND INDUSTRY may be due to seasonal factors similar to West Germany, the results of the other groups mirror the bad labour market situation in East Germany. Being locked into the programmes does not have as much in- 
fluence in terms of negative employment effects here, since the chances that nonparticipants will find a new job are lower anyway. This seems to be valid in particular for women who experience even lower locking-in effects compared to men in East Germany. The employment rates of participating women in July 2000 are between -8.7 (AGRICULTURE) and -12.9 percentage points (CONSTRUCTION AND INDUSTRY) lower than for comparable nonparticipants.

As discussed in Section 3, the average duration of the programmes is less than one year. In fact, most of the participants leave the programmes after around 12 months. In March 2001, about 80\% (74\%) of the male (female) participants in West Germany and about 91\% (92\%) of the male (female) participants in East Germany had left the programmes. Hence, any locking-in effect should start to fade away after that time, which is also reflected by our findings. In July 2001, the effects for all groups in both regions increased, even though they were still significantly negative. This improvement was stronger in West Germany, where the effects in July 2001 for men are between -7.7 (AGRICULTURE) and -15.5 percentage points (OFFICE AND SERVICES) and for women between -11.3 (COMMUNITY SERVICES) and -12.9 percentage points (OTHER). In contrast, the increase in the employment effects in East Germany is smaller but still observable, leading to effects for men between -9.9 (OTHER) and -13.8 percentage points (COMMUNITY SERVICES) and for women between 6.0 (COMMUNITY SERVICES) and -10.4 percentage points (CONSTRUCTION AND INDUSTRY) in that month. Even though this increase is a remarkable development, the crucial question remains if participation in any sector of JCS establishes positive employment effects.

Unfortunately, at the end of the observation period (December 2002) this is only true for two groups: men in West Germany who participated in the sector OfFICE AND SERVICES with an employment effect of 10.1 and women in East Germany who participated in COMMUNITY SERVICES with an effect of 2.3 percentage points. For all other groups, the employment effects at this point in time are still negative or at best insignificant. In particular men in East Germany participating in the sectors CONSTRUCTION AND INDUSTRY and OTHER suffered from participation showing a reduction of -6.0 and -3.4 percentage points in employment rates compared to nonparticipation. Women in East Germany who participated in OFFICE AND SERVICES and OTHER experienced decreased employability, too, as shown by the employment effects of -5.0 and -2.6 percentage points.

These findings indicate some considerable heterogeneity in the effects of JCS with respect to the economic sectors in which they are carried out. The overall picture is rather disappointing, however, since programmes are not able to increase the employment rates of the participating individuals in comparison to the matched nonparticipants. Possible explanations for this unsatisfactory outcome are the design and contents of the programmes. Since JCS provide occupations that are additional in nature, the jobs will in general not comprise activities that are comparable to 'market activities'. Therefore, positive aspects in terms of human capital 
Fig. 4: Sectoral Employment EfFects in East Germany (February 2000 - DeCEMBER 2002) $)^{1,2,3}$
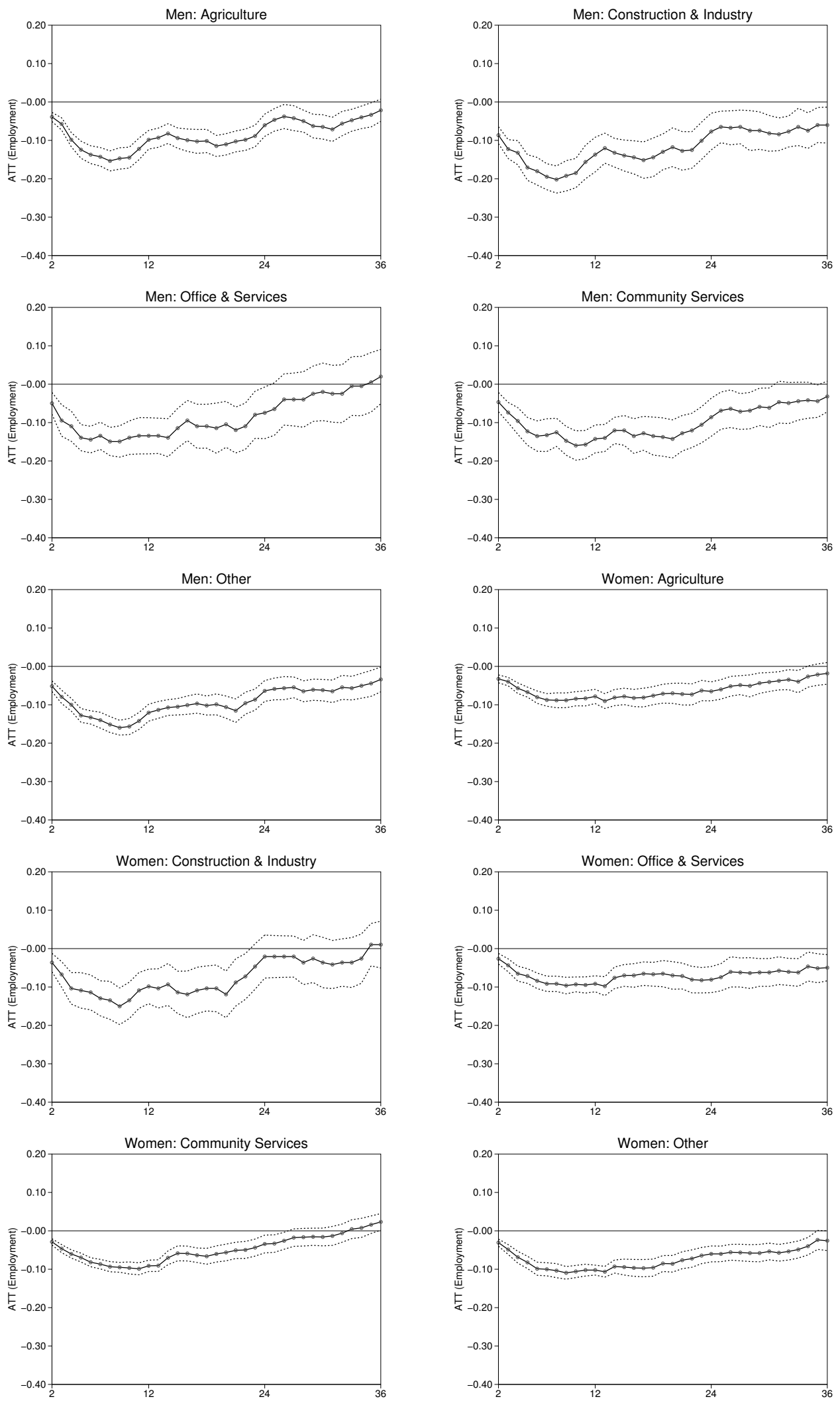

${ }^{1}$ Solid line describes the monthly employment effect. Dotted lines are the upper and lower $95 \%$ confidence limits. 2 Month 2 refers to February 2000, month $12=$ December 2000, month $24=$ December 2001, month $36=$ December 2002.

${ }^{3}$ Effects for groups with less than 100 participants are omitted. 
generation for the participating individuals cannot be expected in most of the sectors.

Taken together, the results (with two exceptions) are rather discouraging and confirm our previous empirical findings on the effectiveness of JCS (see e.g. Hujer, Caliendo and Thomsen 2004, Caliendo, Hujer and Thomsen 2005). Participation in the programmes does not increase the employment chances of individuals in most cases and therefore has to be rated as a failure. What is left to examine is whether we can establish positive effects for the two different types of support (REGULAR and INCREASED) and for the two different providers (PUBLIC and NON-COMMERCIAL). We turn to this question in the following.

\subsection{Gender, Regions and Type of Support}

Tables 3 (West Germany) and 4 (East Germany) contain the employment effects in the different sectors with respect to the two types of support, i.e. REGULAR and INCREASED support. ${ }^{20}$ As mentioned above, INCREASED support should be granted, e.g. for activities that improve the chances for permanent jobs or that aim at the integration of extremely hard-to-place individuals. Therefore, particularly those individuals who have a higher need for assistance should participate in programmes with INCREASED support. ${ }^{21}$ Hence, persons receiving INCREASED support have on average less work experience and a correspondingly shorter last employment duration compared to the participants receiving REGULAR support in most sectors. In addition, in particular in West Germany, the share of persons who previously participated in ALMP programmes is clearly higher than in the REGULAR supported groups. To give an example, whereas the share of West German male participants receiving REGULAR support who participated before is between 18\% (COMMUNITY SERVICES) and 32\% (CONSTRUCTION AND INDUSTRY), the analogues for INCREASED support range from 29\% (COMMUNITY SERVICES) to $38 \%$ (AgRiCUlture). As JCS should be offered only to persons who do not fit the requirements for regular employment or other ALMP programmes, the figures clearly indicate the high degree of placement restrictions of the participants. Unfortunately, for East Germany the picture is more ambiguous. Here, the share of persons receiving INCREASED support who have participated in ALMP programmes before is smaller in most of the groups compared to the participants receiving REGULAR support. However, these shares are still clearly larger compared to West Germany. For men in East Germany (INCREASED support) the shares lie between 38\% (OTHER) and 51\% (Agriculture, Construction AND INDUSTRY, OfFice AND SERVICES), for women between 48\% (CONSTRUCTION AND INDUSTRY) and 62\% (OFFICE AND SERVICES).

Based on these differences, we expect heterogeneity in the effects, too. However, it is a priori unclear in

\footnotetext{
${ }^{20}$ Groups of less than 100 observations have been excluded from evaluation. In the supplementary Appendix, the results over time for the five sectors and the types of support are included (figures C.5 to C.8).

${ }^{21}$ This higher need of assistance becomes obvious when looking at the characteristics of the participating individuals. Detailed information on these characteristics is given in Tables C.1, C.2, C.5, C.6, C.9, C.10, C.13 and C.14 in the supplementary Appendix.
} 
which direction these effects will go. On the one hand, given that persons receiving INCREASED support are worse off in terms of their employment chances, and the programmes are designed especially for them, one could expect stronger positive effects. On the other hand, the results for the sectors overall have shown that JCS work rather poorly in improving the employment chances for the individuals participating. In particular, due to the additional nature of the activities carried out, the argument may be more important that purely maintaining contact to the labour market for the individuals participating does too little to improve their employability. Hence, negative effects are also plausible.

Starting with the results for West Germany (Table 3) we can see the typical development of the employment effects for JCS (see above). Participants, independent of programme sector and type of support, experience negative effects in terms of regular employment shortly after programmes start. Thus, the employment effects for July 2000 are clearly negative. Although there is some heterogeneity in the effects at this point in time, a clear pattern that the type of support determines stronger or weaker locking-in effects could not be established. To give an example, the effects for men receiving REGULAR support range from -15.2 (OFFICE AND SERVICES) to -26.1 percentage points (CONSTRUCTION AND INDUSTRY) and for men receiving INCREASED support, they lie between -20.1 (AGRICULTURE) and -24.8 percentage points (CONSTRUCTION AND INDUSTRY). Due to the small number of observations for women in West Germany we could not estimate the effects for most of the sub-groups.

The same ambiguity is observable in the estimates for July 2000 for East Germany (Table 4). Whereas, for example, male participants in AGRICULTURE are worse off when the activity is INCREASED supported (-16.2 percentage points) compared to male participants receiving REGULAR support (-13.8), the opposite situation exists in the sector COMmunity SERvices. Here, male participants receiving REgUlar support have an employment effect of -15.7 and with INCREASED support of -11.2 percentage points.

However, more important than the development of the effects during the first months after programmes have started are the effects in the short and medium run. A further disaggregation of the effects by the type of support shows a similar development to that described for the sectors. For all of the groups, the employment effects increase over time. The positive employment effects in December 2002 for men in West Germany in the sector OfFICE AND SERVICES are also found with the further differentiation by type of support. Participants receiving REGULAR support experience even higher employment effects with 13.6 percentage points at the end of the observation period. Unfortunately, the group of men receiving INCREASED support in this sector is too small to allow a reasonable interpretation. For the remaining male groups in West Germany, no significant effects could be established. For this reason, participants neither improved nor worsened their employment rates about three years after programmes started compared to the situation had they not participated. Turning to women in West Germany, where we could not find any significant effects in the previous section, the 
Tab. 3: Sectoral Employment Effects by Type of Support - Selected MONTHS (WEST GERMANY) ${ }^{1}$

\begin{tabular}{|c|c|c|c|c|c|c|c|c|}
\hline $\begin{array}{l}\text { West Germany } \\
\text { Men }\end{array}$ & & & & & & & & \\
\hline Sector & $\begin{array}{l}\text { Type of } \\
\text { Support }\end{array}$ & & Jul 00 & Dec 00 & Jul 01 & Dec 01 & Jul 02 & Dec 02 \\
\hline \multirow{4}{*}{ AGRICULTURE } & \multirow{2}{*}{ Regular } & Effect & -0.1675 & -0.1414 & -0.1126 & -0.0707 & -0.0471 & -0.0366 \\
\hline & & S.E. & 0.0208 & 0.0233 & 0.0279 & 0.0254 & 0.0278 & 0.0278 \\
\hline & \multirow{2}{*}{ Increased } & Effect & -0.2050 & $-\mathbf{0 . 1 5 5 0}$ & -0.1100 & -0.0400 & -0.0400 & -0.0050 \\
\hline & & S.E. & 0.0317 & 0.0332 & 0.0461 & 0.0469 & 0.0404 & 0.0382 \\
\hline \multirow{4}{*}{ CONSTRUCTION AND INDUSTRY } & \multirow{2}{*}{ Regular } & Effect & -0.2607 & -0.2308 & -0.1709 & -0.0940 & -0.0684 & -0.0299 \\
\hline & & S.E. & 0.0370 & 0.0291 & 0.0407 & 0.0360 & 0.0366 & 0.0376 \\
\hline & \multirow{2}{*}{ Increased } & Effect & -0.2482 & -0.1752 & -0.0803 & 0.0000 & -0.0365 & 0.0365 \\
\hline & & S.E. & 0.0397 & 0.0491 & 0.0566 & 0.0543 & 0.0496 & 0.0516 \\
\hline \multirow{4}{*}{ OFFICE AND SERVICES } & \multirow{2}{*}{ Regular } & Effect & -0.1520 & -0.1680 & -0.0960 & -0.0320 & 0.0800 & 0.1360 \\
\hline & & S.E. & 0.0381 & 0.0373 & 0.0501 & 0.0470 & 0.0643 & 0.0643 \\
\hline & \multirow{2}{*}{ Increased } & Effect & - & - & - & - & - & - \\
\hline & & S.E. & - & - & - & - & - & - \\
\hline \multirow{4}{*}{ COMMUNITY SERVICES } & \multirow{2}{*}{ Regular } & Effect & -0.2018 & -0.1881 & -0.0688 & -0.0780 & 0.0183 & 0.0275 \\
\hline & & S.E. & 0.0320 & 0.0357 & 0.0365 & 0.0422 & 0.0396 & 0.0385 \\
\hline & \multirow{2}{*}{ Increased } & Effect & - & - & - & - & - & - \\
\hline & & S.E. & - & - & - & - & - & - \\
\hline \multirow{4}{*}{ OTHER } & \multirow{2}{*}{ Regular } & Effect & -0.2231 & -0.1865 & -0.0981 & -0.0481 & -0.0288 & -0.0038 \\
\hline & & S.E. & 0.0199 & 0.0189 & 0.0250 & 0.0326 & 0.0285 & 0.0301 \\
\hline & \multirow{2}{*}{ Increased } & Effect & -0.2115 & -0.1538 & -0.0962 & -0.0913 & -0.0721 & -0.0288 \\
\hline & & S.E. & 0.0344 & 0.0384 & 0.0431 & 0.0410 & 0.0415 & 0.0400 \\
\hline \multicolumn{9}{|l|}{ Women } \\
\hline \multirow{4}{*}{ AGRICULTURE } & \multirow{2}{*}{ Regular } & Effect & - & - & - & - & - & - \\
\hline & & S.E. & - & - & - & - & - & - \\
\hline & \multirow{2}{*}{ Increased } & Effect & - & - & - & - & - & - \\
\hline & & S.E. & - & - & - & - & - & - \\
\hline \multirow{4}{*}{ CONSTRUCTION AND INDUSTRY } & \multirow{2}{*}{ Regular } & Effect & - & - & - & - & - & - \\
\hline & & S.E. & - & - & - & - & - & - \\
\hline & \multirow{2}{*}{ Increased } & Effect & - & - & - & - & - & - \\
\hline & & S.E. & - & - & - & - & - & - \\
\hline \multirow{4}{*}{ OFFICE AND SERVICES } & Regular & Effect & -0.2067 & -0.1732 & -0.0726 & -0.0112 & 0.1061 & 0.1117 \\
\hline & & S.E. & 0.0300 & 0.0358 & 0.0546 & 0.0570 & 0.0557 & 0.0581 \\
\hline & Increased & Effect & - & - & - & - & - & - \\
\hline & & S.E. & - & - & - & - & - & - \\
\hline & Reoular & Effect & -0.2183 & -0.2264 & -0.1617 & -0.1321 & -0.0270 & -0.0108 \\
\hline COMMUNITY SERVICES & & S.E. & 0.0237 & 0.0246 & 0.0315 & 0.0327 & 0.0343 & 0.0339 \\
\hline COMMIUNIIY SERVICES & Increased & Effect & -0.2252 & -0.1982 & -0.1261 & -0.0541 & 0.0450 & 0.1261 \\
\hline & & S.E. & 0.0401 & 0.0407 & 0.0555 & 0.0536 & 0.0572 & 0.0553 \\
\hline & Regular & Effect & -0.2067 & -0.1875 & -0.1058 & -0.0144 & 0.0817 & 0.1202 \\
\hline OTHER & & S.E. & 0.0251 & 0.0356 & 0.0410 & 0.0393 & 0.0404 & 0.0499 \\
\hline ОIНЕК & Increased & Effect & - & - & - & - & - & - \\
\hline & & S.E. & - & - & - & - & - & - \\
\hline
\end{tabular}

Bold letters indicate significance on a $1 \%$ level, italic letters refer to the $5 \%$ level. Standard errors are bootstrapped with 50 replications.

Results refer to NN matching without replacement and a caliper of 0.02 .

1 Groups of less than 100 participants are excluded from estimation.

further differentiation reveals effect heterogeneity and some significant effects. Women receiving INCREASED support in COMmUnity SERVICES experience an improvement of their employability, as the employment effect of 12.6 percentage points in December 2002 indicates. However, it has to be noted that the MSB is not satisfying for this group; after matching, the distributions of the covariates between treated and non-treated individuals differ by $10.48 \%$ on average. Thus, this positive effect has to be interpreted very carefully. The results for women participating with REGULAR support are insignificant. The second group for whom we find 
Tab. 4: Sectoral Employment Effects by Type of Support - Selected MONTHS (EAST GERMANY) ${ }^{1}$

\begin{tabular}{|c|c|c|c|c|c|c|c|c|}
\hline $\begin{array}{l}\text { East Germany } \\
\text { Men }\end{array}$ & & & & & & & & \\
\hline Sector & $\begin{array}{l}\text { Type of } \\
\text { Support }\end{array}$ & & Jul 00 & Dec 00 & Jul 01 & Dec 01 & Jul 02 & $\overline{\text { Dec } 02}$ \\
\hline \multirow{4}{*}{ AGRICULTURE } & \multirow{2}{*}{ Regular } & Effect & -0.1384 & -0.1071 & -0.1250 & -0.0804 & -0.0759 & -0.0536 \\
\hline & & S.E. & 0.0210 & 0.0221 & 0.0255 & 0.0216 & 0.0269 & 0.0255 \\
\hline & \multirow{2}{*}{ Increased } & Effect & -0.1626 & -0.0927 & -0.1127 & -0.0599 & -0.0728 & -0.0300 \\
\hline & & S.E. & 0.0113 & 0.0133 & 0.0172 & 0.0167 & 0.0184 & 0.0193 \\
\hline \multirow{4}{*}{ CONSTRUCTION AND INDUSTRY } & \multirow{2}{*}{ Regular } & Effect & - & - & - & - & - & - \\
\hline & & S.E. & - & - & - & - & - & - \\
\hline & \multirow{2}{*}{ Increased } & Effect & -0.1786 & -0.1161 & -0.1280 & -0.0655 & -0.0595 & -0.0387 \\
\hline & & S.E. & 0.0173 & 0.0217 & 0.0282 & 0.0236 & 0.0303 & 0.0254 \\
\hline \multirow{4}{*}{ OFFICE AND SERVICES } & \multirow{2}{*}{ Regular } & Effect & -0.1182 & -0.1273 & -0.0636 & -0.0273 & 0.0364 & 0.0818 \\
\hline & & S.E. & 0.0331 & 0.0375 & 0.0425 & 0.0463 & 0.0443 & 0.0473 \\
\hline & \multirow{2}{*}{ Increased } & Effect & - & - & - & - & - & - \\
\hline & & S.E. & - & - & - & - & - & - \\
\hline \multirow{4}{*}{ COMMUNITy SERVICES } & \multirow{2}{*}{ Regular } & Effect & -0.1573 & -0.1331 & -0.1250 & -0.1331 & -0.0927 & -0.0645 \\
\hline & & S.E. & 0.0231 & 0.0243 & 0.0270 & 0.0230 & 0.0285 & 0.0289 \\
\hline & \multirow{2}{*}{ Increased } & Effect & -0.1118 & -0.1242 & -0.0932 & -0.0311 & -0.0062 & -0.0559 \\
\hline & & S.E. & 0.0315 & 0.0288 & 0.0397 & 0.0439 & 0.0473 & 0.0451 \\
\hline \multirow{4}{*}{ OTHER } & \multirow{2}{*}{ Regular } & Effect & -0.1078 & -0.0929 & -0.1190 & -0.0632 & -0.0335 & 0.0149 \\
\hline & & S.E. & 0.0218 & 0.0209 & 0.0295 & 0.0247 & 0.0302 & 0.0233 \\
\hline & \multirow{2}{*}{ Increased } & Effect & -0.1439 & -0.1254 & -0.0954 & -0.0670 & -0.0570 & -0.0157 \\
\hline & & S.E. & 0.0143 & 0.0147 & 0.0213 & 0.0163 & 0.0186 & 0.0161 \\
\hline \multicolumn{9}{|l|}{ Women } \\
\hline \multirow{4}{*}{ AGRICULTURE } & \multirow{2}{*}{ Regular } & Effect & -0.0785 & -0.0579 & -0.0579 & -0.0620 & -0.0496 & -0.0165 \\
\hline & & S.E. & 0.0181 & 0.0199 & 0.0248 & 0.0226 & 0.0291 & 0.0261 \\
\hline & \multirow{2}{*}{ Increased } & Effect & -0.0861 & -0.0888 & -0.0848 & -0.0740 & -0.0458 & -0.0350 \\
\hline & & S.E. & 0.0099 & 0.0122 & 0.0135 & 0.0132 & 0.0142 & 0.0139 \\
\hline \multirow{4}{*}{ CONSTRUCTION AND INDUSTRY } & \multirow{2}{*}{ Regular } & Effect & - & - & - & - & - & - \\
\hline & & S.E. & - & - & - & - & - & - \\
\hline & \multirow{2}{*}{ Increased } & Effect & -0.1103 & -0.0966 & -0.0759 & -0.0483 & -0.0483 & -0.0552 \\
\hline & & S.E. & 0.0320 & 0.0270 & 0.0334 & 0.0379 & 0.0360 & 0.0334 \\
\hline \multirow{4}{*}{ OFFICE AND SERVICES } & Regular & Effect & -0.0852 & -0.0877 & -0.0602 & -0.0576 & -0.0326 & -0.0251 \\
\hline & & S.E. & 0.0159 & 0.0168 & 0.0226 & 0.0224 & 0.0255 & 0.0241 \\
\hline & & Effect & -0.1423 & -0.1301 & -0.0772 & -0.0569 & -0.0447 & -0.0163 \\
\hline & Inc & S.E. & 0.0240 & 0.0212 & 0.0278 & 0.0256 & 0.0290 & 0.0299 \\
\hline & & Effect & -0.0808 & -0.0927 & -0.0459 & -0.0331 & -0.0165 & 0.0294 \\
\hline SEPI & Reg & S.E. & 0.0078 & 0.0097 & 0.0137 & 0.0127 & 0.0147 & 0.0151 \\
\hline COMMUNITY SERVICES & & Effect & -0.0847 & -0.0889 & -0.0569 & -0.0139 & 0.0056 & 0.0250 \\
\hline & Increased & S.E. & 0.0112 & 0.0114 & 0.0127 & 0.0169 & 0.0207 & 0.0178 \\
\hline & Res & Effect & -0.0794 & -0.0967 & -0.0846 & -0.0829 & -0.0535 & -0.0328 \\
\hline OTHER & & S.E. & 0.0112 & 0.0112 & 0.0182 & 0.0185 & 0.0191 & 0.0220 \\
\hline & $\operatorname{Inc}$ & Effect & -0.0732 & -0.0610 & -0.0646 & -0.0415 & -0.0268 & -0.0024 \\
\hline & Increased & S.E. & 0.0117 & 0.0101 & 0.0147 & 0.0119 & 0.0154 & 0.0145 \\
\hline
\end{tabular}

positive treatment effects at the end of the observation period are women who receive REGULAR support in the sector OTHER (12.0 percentage points). No other significant effects could be established. Positive effects could not be established for any of the groups in East Germany (Table 4). In contrast, we find negative effects for men in AgRICULTURE (-5.4 percentage points) and COMMUNITY SERVICES (-6.5) who receive REGULAR support. For women, we find only one significant effect, namely for participants receiving INCREASED support in AgRiculture with -3.5 percentage points. 
Hence, we can give no clear recommendation on which type of support should be preferred. There are only two groups with positive effects. For the first group (men in OFFICE AND SERVICES in West Germany) we can only estimate the effects of REGULAR support, since the number of participants receiving INCREASED support is too small. For the second group (women in COMMUNITY SERVICES), the findings should not be overemphasised since the matching quality indicators (MSB and number of treated individuals lost due to common support) are not favourable. However, for most of the groups, participation in JCS has no effect at all.

\subsection{Gender, Regions and Providers}

Finally, we analyse the effect heterogeneity in the programme sectors taking into consideration the different types of implementing institutions. As we have seen above, JCS are provided by three different types of institutions: those in the PUBLIC sector, in NON-COMMERCIAL institutions, and in PRIVATE BUSINESSES. Due to the small numbers of participants in JCS in PRIVATE BUSINESSES, we do not analyse these effects. Moreover, particularly for West Germany, the differentiation by types of providers leads to numerous groups with less than 100 participants. Hence, we are only able to evaluate the effects for six male and three female groups. In East Germany, the differentiation is not so problematic and we have to exclude only three of the 20 possible groups.

The results for West Germany (Table 5) show that there are no clear differences with respect to locking-in effects during the first months after participation began. For example, men in AGRICULTURE in the PUBLIC SECTOR had an employment effect of -19.8 percentage points in July 2000, whereas those participating in a programme provided by a NON-COMMERCIAL institution experienced a negative employment effect of -18.5 percentage point in that month. Similar results are found for male participants in the sector OTHER (-21.9 PUbLIC/-20.5 NON-COMMERCIAL). For women in COMMUNiTy SERVICES, the relation is reversed, with -19.8 percentage points in the PUBLIC SECTOR and -21.0 percentage points in the NON-COMMERCIAL sector. Although the effects increase in the following months, there are no significant positive effects at all at the end of our observation period in December 2002. For this reason, no differences that are due to the implementing institutions in the effects of JCS could be established in the different programme sectors.

Unfortunately, the situation in East Germany (Table 6) is different, but not better. Similar to the results in the former sections, the locking-in effects are smaller in East Germany compared to the West. However, differences between the types of providers in the sectors can be observed. For example, whereas male participants in AGRICULTURE experience an employment effect of -14.8 percentage points if the programme is offered by a PUBLIC provider, participants in the same sector at a NON-COMMERCIAL provider have reduced employment rates of -12.5 percentage points. Men and women participating in the sector CONSTRUCTION 
Tab. 5: Sectoral Employment Effects by Type of Provider - Selected Months (West Germany) ${ }^{1}$

\begin{tabular}{|c|c|c|c|c|c|c|c|c|}
\hline $\begin{array}{l}\text { West Germany } \\
\text { Men }\end{array}$ & & & & & & & & \\
\hline Sector & Provider & & Jul 00 & Dec 00 & Jul 01 & Dec 01 & Jul 02 & Dec 02 \\
\hline \multirow{4}{*}{ AGRICULTURE } & \multirow{2}{*}{ Public } & Effect & -0.1976 & -0.1108 & -0.1138 & -0.0659 & -0.0449 & -0.0120 \\
\hline & & S.E. & 0.0228 & 0.0218 & 0.0239 & 0.0258 & 0.0297 & 0.0228 \\
\hline & \multirow{2}{*}{ Non-Commercial } & Effect & -0.1849 & -0.1681 & -0.0840 & -0.0378 & 0.0168 & 0.0294 \\
\hline & & S.E. & 0.0316 & 0.0308 & 0.0337 & 0.0373 & 0.0363 & 0.0325 \\
\hline \multirow{4}{*}{ CONSTRUCTION AND INDUSTRY } & \multirow{2}{*}{ Public } & Effect & - & - & - & - & - & - \\
\hline & & S.E. & - & - & - & - & - & - \\
\hline & \multirow{2}{*}{ Non-Commercial } & Effect & -0.1932 & -0.1818 & -0.1023 & -0.0379 & -0.0455 & -0.0076 \\
\hline & & S.E. & 0.0274 & 0.0264 & 0.0365 & 0.0328 & 0.0356 & 0.0363 \\
\hline \multirow{4}{*}{ OFFICE AND SERVICES } & \multirow{2}{*}{ Public } & Effect & - & - & - & - & - & - \\
\hline & & S.E. & - & - & - & - & - & - \\
\hline & \multirow{2}{*}{ Non-Commercial } & Effect & - & - & - & - & - & - \\
\hline & & S.E. & - & - & - & - & - & - \\
\hline \multirow{4}{*}{ COMMUNITY SERVICES } & \multirow{2}{*}{ Public } & Effect & - & - & - & - & - & - \\
\hline & & S.E. & - & - & - & - & - & - \\
\hline & \multirow{2}{*}{ Non-Commercial } & Effect & -0.2283 & -0.2165 & -0.1496 & -0.1024 & -0.0472 & 0.0197 \\
\hline & & S.E. & 0.0302 & 0.0329 & 0.0380 & 0.0373 & 0.0383 & 0.0362 \\
\hline \multirow{4}{*}{ OTHER } & \multirow{2}{*}{ Public } & Effect & -0.2189 & -0.1990 & -0.1592 & -0.1343 & -0.0945 & -0.0348 \\
\hline & & S.E. & 0.0365 & 0.0360 & 0.0377 & 0.0366 & 0.0377 & 0.0359 \\
\hline & \multirow{2}{*}{ Non-Commercial } & Effect & -0.2047 & -0.1599 & -0.0981 & -0.0661 & -0.0235 & 0.0043 \\
\hline & & S.E. & 0.0215 & 0.0263 & 0.0252 & 0.0256 & 0.0297 & 0.0309 \\
\hline \multicolumn{9}{|l|}{ Women } \\
\hline \multirow{4}{*}{ AGRICULTURE } & \multirow{2}{*}{ Public } & Effect & - & - & - & - & - & - \\
\hline & & S.E. & - & - & - & - & - & - \\
\hline & \multirow{2}{*}{ Non-Commercial } & Effect & - & - & - & - & - & - \\
\hline & & S.E. & - & - & - & - & - & - \\
\hline \multirow{4}{*}{ CONSTRUCTION AND INDUSTRY } & \multirow{2}{*}{ Public } & Effect & - & - & - & - & - & - \\
\hline & & S.E. & - & - & - & - & - & - \\
\hline & \multirow{2}{*}{ Non-Commercial } & Effect & - & - & - & - & - & - \\
\hline & & S.E. & - & - & - & - & - & - \\
\hline \multirow{4}{*}{ OFFICE AND SERVICES } & Public & Effect & - & - & - & - & - & - \\
\hline & Puonic & S.E. & - & - & - & - & - & - \\
\hline & Non-Commercial & Effect & - & - & - & - & - & - \\
\hline & Non-commercial & S.E. & - & - & - & - & - & - \\
\hline & Public & Effect & -0.1984 & -0.1984 & -0.1429 & -0.0635 & -0.0079 & -0.0079 \\
\hline COMMUNITY SERVICES & Puonc & S.E. & 0.0411 & 0.0395 & 0.0446 & 0.0484 & 0.0593 & 0.0564 \\
\hline COMMUNITY SERVICES & Non-Commercial & Effect & -0.2099 & -0.2431 & -0.1160 & -0.0939 & 0.0138 & 0.0442 \\
\hline & son-commercial & S.E. & 0.0200 & 0.0247 & 0.0297 & 0.0326 & 0.0304 & 0.0318 \\
\hline & Public & Effect & - & - & - & - & - & - \\
\hline OTHER & & S.E. & - & - & - & - & - & - \\
\hline & Non-Commercial & Effect & -0.1937 & -0.2304 & -0.1257 & -0.0785 & 0.0000 & 0.0105 \\
\hline & Nom-comintercia & S.E. & 0.0249 & 0.0355 & 0.0424 & 0.0430 & 0.0455 & 0.0454 \\
\hline
\end{tabular}

AND INDUSTRY at a NON-COMMERCIAL provider experience the strongest locking-in effects, which may be due to seasonal employment as mentioned above. Although a further improvement of the employment rates up to the end of the observation period can be observed, most of the effects are insignificantly different from zero in December 2002. But, it has to be noted that the effects for men in the sector AgRICULTURE (-5.3 percentage points) as well as for women in OTHER (-3.8) accomplished by NON-COMMERCIAL providers are significantly negative. In these two cases the activities provided by NON-COMMERCIAL institutions tend to harm the employment chances even more than at the PUBLIC providers. 
Tab. 6: Sectoral Employment Effects by Type of Provider - Selected Months (EAST GERMANY) ${ }^{1}$

\begin{tabular}{|c|c|c|c|c|c|c|c|c|}
\hline $\begin{array}{l}\text { East Germany } \\
\text { Men }\end{array}$ & & & & & & & & \\
\hline Sector & Provider & & Jul 00 & Dec 00 & Jul 01 & Dec 01 & Jul 02 & Dec 02 \\
\hline \multirow{4}{*}{ AGRICULTURE } & \multirow{2}{*}{ Public } & Effect & -0.1475 & -0.1079 & -0.1403 & -0.0827 & -0.0432 & -0.0180 \\
\hline & & S.E. & 0.0222 & 0.0201 & 0.0260 & 0.0196 & 0.0229 & 0.0243 \\
\hline & \multirow{2}{*}{ Non-Commercial } & Effect & -0.1246 & -0.0902 & -0.0918 & -0.0689 & -0.0754 & -0.0525 \\
\hline & & S.E. & 0.0141 & 0.0133 & 0.0176 & 0.0158 & 0.0153 & 0.0141 \\
\hline \multirow{4}{*}{ CONSTRUCTION AND INDUSTRY } & \multirow{2}{*}{ Public } & Effect & -0.1556 & -0.1667 & -0.1000 & -0.0667 & -0.0500 & -0.0611 \\
\hline & & S.E. & 0.0290 & 0.0261 & 0.0377 & 0.0393 & 0.0326 & 0.0319 \\
\hline & \multirow{2}{*}{ Non-Commercial } & Effect & -0.1827 & -0.1154 & -0.1538 & -0.0913 & -0.0721 & -0.0433 \\
\hline & & S.E. & 0.0289 & 0.0287 & 0.0368 & 0.0307 & 0.0358 & 0.0286 \\
\hline \multirow{4}{*}{ OFFICE AND SERVICES } & \multirow{2}{*}{ Public } & Effect & - & - & - & - & - & - \\
\hline & & S.E. & - & - & - & - & - & - \\
\hline & \multirow{2}{*}{ Non-Commercial } & Effect & -0.1290 & -0.1048 & -0.1290 & -0.0645 & 0.0161 & 0.0484 \\
\hline & & S.E. & 0.0354 & 0.0325 & 0.0393 & 0.0373 & 0.0519 & 0.0453 \\
\hline \multirow{4}{*}{ COMMUNITY SERVICES } & \multirow{2}{*}{ Public } & Effect & - & - & - & - & - & - \\
\hline & & S.E. & - & - & - & - & - & - \\
\hline & \multirow{2}{*}{ Non-Commercial } & Effect & -0.1524 & -0.1494 & -0.1128 & -0.0976 & -0.0488 & -0.0122 \\
\hline & & S.E. & 0.0221 & 0.0178 & 0.0246 & 0.0274 & 0.0209 & 0.0268 \\
\hline \multirow{4}{*}{ OTHER } & \multirow{2}{*}{ Public } & Effect & -0.1719 & -0.0990 & -0.1146 & -0.0990 & -0.0573 & -0.0260 \\
\hline & & S.E. & 0.0286 & 0.0273 & 0.0338 & 0.0312 & 0.0338 & 0.0299 \\
\hline & \multirow{2}{*}{ Non-Commercial } & Effect & -0.1434 & -0.1298 & -0.0943 & -0.0464 & -0.0464 & -0.0055 \\
\hline & & S.E. & 0.0144 & 0.0106 & 0.0156 & 0.0178 & 0.0167 & 0.0139 \\
\hline \multicolumn{9}{|l|}{ Women } \\
\hline \multirow{4}{*}{ AGRICULTURE } & \multirow{2}{*}{ Public } & Effect & -0.0818 & -0.0881 & -0.0597 & -0.0723 & -0.0377 & -0.0314 \\
\hline & & S.E. & 0.0155 & 0.0161 & 0.0217 & 0.0170 & 0.0213 & 0.0204 \\
\hline & \multirow{2}{*}{ Non-Commercial } & Effect & -0.0866 & -0.0677 & -0.0772 & -0.0409 & -0.0252 & -0.0142 \\
\hline & & S.E. & 0.0116 & 0.0091 & 0.0171 & 0.0153 & 0.0187 & 0.0157 \\
\hline \multirow{4}{*}{ CONSTRUCTION AND INDUSTRY } & \multirow{2}{*}{ Public } & Effect & - & - & - & - & - & - \\
\hline & & S.E. & - & - & - & - & - & - \\
\hline & \multirow{2}{*}{ Non-Commercial } & Effect & -0.1157 & -0.0579 & -0.0579 & 0.0165 & -0.0165 & 0.0165 \\
\hline & & S.E. & 0.0292 & 0.0274 & 0.0357 & 0.0375 & 0.0375 & 0.0373 \\
\hline \multirow{4}{*}{ OFFICE AND SERVICES } & Public & Effect & -0.0939 & -0.0903 & -0.0614 & -0.0614 & -0.0578 & -0.0181 \\
\hline & Public & S.E. & 0.0135 & 0.0169 & 0.0283 & 0.0252 & 0.0270 & 0.0271 \\
\hline & $\mathrm{N}$ & Effect & -0.1145 & -0.1205 & -0.0663 & -0.0512 & -0.0120 & -0.0181 \\
\hline & Non-commercial & S.E. & 0.0171 & 0.0164 & 0.0245 & 0.0219 & 0.0265 & 0.0227 \\
\hline & Public & Effect & -0.0880 & -0.1129 & -0.0745 & -0.0474 & -0.0451 & -0.0316 \\
\hline COMMUNITY SERVICES & Puonc & S.E. & 0.0121 & 0.0134 & 0.0219 & 0.0232 & 0.0272 & 0.0250 \\
\hline COMMUNHY SERVICES & ommercial & Effect & -0.0984 & -0.1037 & -0.0689 & -0.0386 & -0.0182 & 0.0144 \\
\hline & son-commerctal & S.E. & 0.0081 & 0.0092 & 0.0127 & 0.0132 & 0.0119 & 0.0137 \\
\hline & Pul & Effect & -0.1000 & -0.0938 & -0.0688 & -0.0531 & -0.0313 & 0.0000 \\
\hline OTHER & & S.E. & 0.0163 & 0.0168 & 0.0212 & 0.0231 & 0.0234 & 0.0204 \\
\hline & Non-Commercial & Effect & -0.1032 & -0.0942 & -0.0862 & -0.0581 & -0.0481 & -0.0381 \\
\hline & Noni-comintercial & S.E. & 0.0091 & 0.0096 & 0.0132 & 0.0133 & 0.0153 & 0.0153 \\
\hline
\end{tabular}

Due to the small number of observations when considering JCS with respect to economic sectors of the activities and the types of providers in West Germany, the estimated employment effects do not provide a clear indication of how to change the design of the programmes. For East Germany, the results provide the same disappointing picture as the other possible sources of effect heterogeneity. However, given the similarity of the results for both types of providers - aside from the two exceptions mentioned above for East Germany neither the PUBLIC nor the NON-COMMERCIAL institutions are able to achieve a relevant lead compared to the other in terms of a successful programme. 


\section{Conclusions}

JCS have been a major ALMP programme in Germany in the 1990s and the early 2000s. They are implemented in different sectors of the economy (e.g. Agriculture, CONSTRUCTION AND INDUSTRY or OfFice And Services), by different service providers (e.g. PubliC and Non-COMmercial institutions) and there are also two types of support (REGULAR and INCREASED support). Furthermore, the unemployed workers promoted by these programmes also differ with respect to their individual employability. For these reasons, effect heterogeneity is an important topic for programme evaluation. Identifying effect heterogeneity can help to improve the design and implementation of future programmes, but requires rich and informative data. Fortunately, we have at our disposal administrative data of the FEA that cover information on more than 11,000 participants and about 220,000 nonparticipants.

Whereas in Caliendo, Hujer and Thomsen (2005), we analysed the employment effects of JCS on the participants with respect to group-specific and regional heterogeneity, we focus here explicitly on effect heterogeneity caused by differences in the implementation of the programmes. We are able to evaluate the employment effects of participants up to almost three years after programmes started. The descriptive analysis of participants and nonparticipants shows several notable differences between sectors, but also between gender and regions, that were accounted for in the estimation of the effects. Consequently, the analysis has been conducted separately for men and women in West and East Germany and differentiated by sectors, providers and types of support.

The overall findings are rather disappointing. Although we find positive employment effects at the end of our observation period in December 2002 for some groups, i.e. men in West Germany in OFFICE AND SERVICES and women in East Germany in COMMUNity SERVICES, for all other groups, the programmes either have no effect, or they even harm the employment chances of the participants. In East Germany, for example, men participating in the sectors CONSTRUCTION AND INDUSTRY and OTHER as well as women in OFFICE AND SERVICES and OTHER experience a loss of employability. The results for the other aspects in consideration (type of provider, type of support) are similar. Furthermore, the results show that participation in JCS is associated with strong locking-in effects during the time of the programmes. Although this finding is not surprising as JCS are some kind of work, it may be a major reason for the unsatisfying picture of the programme effects in almost all groups at the end of the observation period.

Together with our previous empirical findings (see Caliendo, Hujer and Thomsen 2005) it is now possible to judge the performance of JCS in Germany based on several sources of possible effect heterogeneity. In total, it can be seen that JCS are in general unable to improve the re-integration probability into regular employment for participating unemployed persons. The results are also concordant with recent evaluation studies of JCS 
for other countries, finding large locking-in effects and overall negative effects - see e.g. Sianesi (2004) for Sweden, Firth, Payne and Payne (1999) for the UK, Gerfin and Lechner (2002) for Switzerland and Martin and Grubb (2001) for an overview of OECD countries.

However, we have also shown that the programmes work in some settings. Hence, a clear policy recommendation is to focus programmes more on problem groups in the labour market and thereby reduce the number of participants. Clearly, this was not the case in Germany for a long period (in particular in East Germany, where JCS have been used on a large scale during the 1990s and early 2000s) and is one possible explanation for the disappointing effects. For all these reasons, tailoring the programmes more specifically to fit the needs of the participants may also help to increase their efficiency. Finally, a further possible explanation for the negative effects which has to be mentioned is the connection between participation and the unemployment benefit system. During our observation period, participation in JCS renewed the eligibility for unemployment benefits for participants in the same way as regular employment. Hence, participants who finished their programme were faced with possibly bad incentives to search and apply for regular employment. Meanwhile, this problematic design was changed from 2004 onwards. Together with a reduction of the number of participants and a better orientation of the programmes to the needs of the participants, JCS will play a minor role for specific problem groups in the labour market in the future.

\section{References}

Blien, U., F. Hirschenauer, M. Arendt, H. J. Braun, D.-M. Gunst, S. Kilcioglu, H. Kleinschmidt, M. Musati, H. Roß, D. Vollkommer, J. Wein (2004), Typisierung von Bezirken der Agenturen der Arbeit. Zeitschrift für Arbeitsmarktforschung, Vol. 37(2), pp. 146-175.

Blundell, R., L. Dearden, B. Sianesi (2004), Evaluating the Impact of Education on Earnings in the UK: Models, Methods and Results from the NCDS. Working Paper No. 03/20, The Institute for Fiscal Studies.

Bundesanstalt für Arbeit (2002a), Arbeitsmarkt 2001. Amtliche Nachrichten der Bundesanstalt für Arbeit, 50. Jahrgang, Nuremberg.

Bundesanstalt für Arbeit (2002b), Daten zu den Eingliederungsbilanzen 2001. Amtliche Nachrichten der Bundesanstalt für Arbeit, 50. Jahrgang, Nürnberg.

Caliendo, M., R. Hujer, S. Thomsen (2005), The Employment Effects of Job Creation Schemes in Germany A Microeconometric Evaluation. Discussion Paper No. 1512, IZA, Bonn. 
Caliendo, M., S. Kopeinig (2005), Some Practical Guidance for the Implementation of Propensity Score Matching. Discussion Paper No. 1588, IZA, Bonn.

Cochran, W., D. Rubin (1973), Controlling Bias in Observational Studies. Sankyha, Vol. 35, pp. 417-446.

Eichler, M., M. Lechner (2002), An Evaluation of Public Employment Programmes in the East German State of Sachsen-Anhalt. Labour Economics, Vol. 9, pp. 143-186.

Firth, D., C. Payne, J. Payne (1999), Efficacy of Programmes for the Unemployed: Discrete Time Modelling of Duration Data from a Matched Comparison Study. Journal of the Royal Statistical Society, Vol. 162(1), pp. 111-120.

Fitzenberger, B., S. Speckesser (2005), Employment Effects of the Provision of Specific Professional Skills and Techniques in Germany. Working Paper, Goethe-University Frankfurt.

Fredriksson, P., P. Johansson (2004), Dynamic Treatment Assignment - The Consequences for Evaluations using Observational Data. Discussion Paper IFAU, Uppsala.

Gerfin, M., M. Lechner (2002), A Microeconometric Evaluation of the Active Labour Market Policy in Switzerland. The Economic Journal, Vol. 112, pp. 854-893.

Hübler, O. (1997), Evaluation beschäftigungspolitischer Maßnahmen in Ostdeutschland. Jahrbücher für Nationalökonomie und Statistik, Vol. 216, pp. 21-44.

Heckman, J., H. Ichimura, J. Smith, P. Todd (1998), Characterizing Selection Bias Using Experimental Data. Econometrica, Vol. 66, pp. 1017-1098.

Heckman, J., J. Smith (1999), The Pre-Program Earnings Dip and the Determinants of Participation in a Social Program: Implications for Simple Program Evaluation Strategies. Working Paper No. 6983, National Bureau of Economic Research.

Hujer, R., M. Caliendo, S. Thomsen (2004), New Evidence on the Effects of Job Creation Schemes in Germany - A Matching Approach with Threefold Heterogeneity. Research in Economics, Vol. 58(4), pp. $257-302$.

Imbens, G. (2000), The Role of the Propensity Score in Estimating Dose-Response Functions. Biometrika, Vol. 87(3), pp. 706-710.

Imbens, G. (2004), Nonparametric Estimation of Average Treatment Effects under Exogeneity: A Review. The Review of Economics and Statistics, Vol. 86(1), pp. 4-29. 
Kraus, F., P. Puhani, V. Steiner (2000), Do Public Works Programs Work? Some Unpleasant Results from the East German Experience. in S. Polachek (ed.), Research in Labour Economics, JAI Press.

Lechner, M. (2001), Identification and Estimation of Causal Effects of Multiple Treatments Under the Conditional Independence Assumption. in: Econometric Evaluation of Labour Market Policies, ed. by M. Lechner, and F. Pfeiffer, Physica-Verlag, Heidelberg.

Lechner, M., R. Miquel, C. Wunsch (2005a), Long-Run Effects of Public Sector Sponsored Training in West Germany. Discussion Paper No. 1443, IZA, Bonn.

Lechner, M., R. Miquel, C. Wunsch (2005b), The Curse and Blessing of Training the Unemployed in a Changing Economy: The Case of East Germany After Unification. Discussion Paper No. 1684, IZA, Bonn.

Leuven, E., B. Sianesi (2003), PSMATCH2: Stata Module to Perform Full Mahalanobis and Propensity Score Matching, Common Support Graphing, and Covariate Imbalance Testing.

Software, http://ideas.repec.org/c/boc/bocode/s432001.html.

Martin, P., D. Grubb (2001), What Works and for Whom: A Review of OECD Countries Experiences with Active Labour Market Policies. Swedish Economic Policy Review, Vol. 8, pp. 9-56.

Rosenbaum, P., D. Rubin (1983), The Central Role of the Propensity Score in Observational Studies for Causal Effects. Biometrika, Vol. 70, pp. 41-50.

Rosenbaum, P., D. Rubin (1985), Constructing a Control Group Using Multivariate Matched Sampling Methods that Incorporate the Propensity Score. The American Statistican, Vol. 39, pp. 33-38.

Roy, A. (1951), Some Thoughts on the Distribution of Earnings. Oxford Economic Papers, Vol. 3, pp. 135145.

Rubin, D. (1974), Estimating Causal Effects to Treatments in Randomised and Nonrandomised Studies. Journal of Educational Psychology, Vol. 66, pp. 688-701.

Sianesi, B. (2004), An Evaluation of the Active Labour Market Programmes in Sweden. The Review of Economics and Statistics, Vol. 86(1), pp. 133-155.

Smith, J., P. Todd (2005), Does Matching Overcome LaLonde's Critique of Nonexperimental Estimators? Journal of Econometrics, Vol. 125(1-2), pp. 305-353. 
Steiner, V., F. Kraus (1995), Haben Teilnehmer an Arbeitsbeschaffungsmaßnahmen in Ostdeutschland bessere Wiederbeschäftigungschancen als Arbeitslose? IAB - Beiträge zur Arbeitsmarkt- und Berufsforschung 192, pp. 387-423. 


\section{Appendix}

Tab. A.1: Selected Descriptives for Men in West Germany

\begin{tabular}{|c|c|c|c|c|c|c|}
\hline Variables & $\begin{array}{l}\text { NON- } \\
\text { PART. }\end{array}$ & AGRICUL. & $\begin{array}{l}\text { CONSTR. } \\
\text { AND IN- } \\
\text { DUSTRY }\end{array}$ & $\begin{array}{c}\text { OFFICE } \\
\text { AND } \\
\text { SERVICES }\end{array}$ & $\begin{array}{l}\text { COMM. } \\
\text { SERVICES }\end{array}$ & OTHER \\
\hline Number of observations & 44,095 & 584 & 371 & 131 & 320 & 734 \\
\hline Programme Duration (in days) & & 261.5 & 279.1 & 336.7 & 285.2 & 277.1 \\
\hline \multicolumn{7}{|l|}{ Socio-Demographic Variables } \\
\hline Age & 43.22 & 39.02 & 35.01 & 42.65 & 34.98 & 36.88 \\
\hline Married & 0.52 & 0.37 & 0.37 & 0.38 & 0.30 & 0.34 \\
\hline Number of children & 0.41 & 0.51 & 0.44 & 0.41 & 0.38 & 0.39 \\
\hline \multicolumn{7}{|l|}{ Health restrictions } \\
\hline No health restrictions & 0.68 & 0.74 & 0.81 & 0.58 & 0.76 & 0.74 \\
\hline Acc. DoR, $80 \%$ and over & 0.01 & 0.02 & 0.01 & 0.07 & 0.02 & 0.02 \\
\hline Acc. DoR, $50 \%$ to under $80 \%$ & 0.06 & 0.05 & 0.03 & 0.15 & 0.07 & 0.06 \\
\hline Acc. DoR, $30 \%$ to under $50 \%$ & 0.00 & 0.01 & 0.00 & 0.02 & 0.01 & 0.00 \\
\hline Acc. DoR, $30 \%$ to under $50 \%$, no equalis. & 0.05 & 0.03 & 0.03 & 0.06 & 0.02 & 0.02 \\
\hline Other health restrictions & 0.20 & 0.15 & 0.12 & 0.12 & 0.12 & 0.15 \\
\hline Rehabilitation attendant & 0.06 & 0.05 & 0.06 & 0.11 & 0.06 & 0.04 \\
\hline Placement restrictions & 0.22 & 0.16 & 0.14 & 0.22 & 0.16 & 0.18 \\
\hline \multicolumn{7}{|l|}{ Qualification Variables } \\
\hline \multicolumn{7}{|l|}{ Professional Training } \\
\hline Without compl. prof. training, no CSE & 0.15 & 0.34 & 0.31 & 0.07 & 0.18 & 0.24 \\
\hline Without compl. prof. training, with CSE & 0.34 & 0.36 & 0.44 & 0.15 & 0.34 & 0.38 \\
\hline Industrial training & 0.44 & 0.27 & 0.24 & 0.47 & 0.30 & 0.31 \\
\hline Full-time vocational school & 0.01 & 0.00 & 0.01 & 0.02 & 0.02 & 0.01 \\
\hline Technical school & 0.02 & 0.01 & 0.00 & 0.10 & 0.04 & 0.01 \\
\hline Polytechnic & 0.01 & 0.00 & 0.00 & 0.07 & 0.05 & 0.01 \\
\hline College, university & 0.02 & 0.01 & 0.00 & 0.14 & 0.08 & 0.03 \\
\hline \multicolumn{7}{|l|}{ Occupational group } \\
\hline Plant cultivation, breeding, fishery & 0.04 & 0.17 & 0.08 & 0.04 & 0.03 & 0.06 \\
\hline Mining, mineral extraction & 0.01 & 0.00 & 0.01 & 0.00 & 0.00 & 0.00 \\
\hline Manufacturing & 0.48 & 0.52 & 0.67 & 0.17 & 0.41 & 0.56 \\
\hline Technical professions & 0.05 & 0.01 & 0.02 & 0.17 & 0.03 & 0.03 \\
\hline Service professions & 0.41 & 0.28 & 0.20 & 0.63 & 0.50 & 0.33 \\
\hline Other professions & 0.02 & 0.02 & 0.03 & 0.00 & 0.03 & 0.03 \\
\hline \multicolumn{7}{|l|}{ Professional Rank } \\
\hline Unskilled worker & 0.24 & 0.45 & 0.39 & 0.11 & 0.18 & 0.28 \\
\hline Skilled worker & 0.15 & 0.06 & 0.07 & 0.05 & 0.07 & 0.09 \\
\hline White-collar worker, simple occupations & 0.07 & 0.02 & 0.03 & 0.14 & 0.09 & 0.05 \\
\hline White-collar worker, advanced occupations & 0.05 & 0.01 & 0.01 & 0.19 & 0.06 & 0.03 \\
\hline Other & 0.49 & 0.46 & 0.51 & 0.50 & 0.59 & 0.55 \\
\hline Qualification (with work experience) & 0.93 & 0.92 & 0.88 & 0.84 & 0.84 & 0.85 \\
\hline \multicolumn{7}{|l|}{ Career Variables } \\
\hline Duration last employment (months) & 72.08 & 16.71 & 18.57 & 27.14 & 18.97 & 20.51 \\
\hline \multicolumn{7}{|l|}{ Duration of unemployment (weeks) } \\
\hline$<13$ & 0.28 & 0.22 & 0.28 & 0.18 & 0.30 & 0.28 \\
\hline $13-52$ & 0.32 & 0.33 & 0.37 & 0.31 & 0.38 & 0.34 \\
\hline$>52$ & 0.41 & 0.45 & 0.35 & 0.51 & 0.32 & 0.38 \\
\hline Number of placement propositions & 3.60 & 8.17 & 6.87 & 9.23 & 7.08 & 7.74 \\
\hline Last contact to job center (weeks) & 2.54 & 2.27 & 2.38 & 2.97 & 2.49 & 2.61 \\
\hline \multicolumn{7}{|l|}{ Programme before unemployment } \\
\hline No further education or programme & 0.90 & 0.69 & 0.66 & 0.66 & 0.78 & 0.74 \\
\hline Further education compl., cont. education & 0.07 & 0.10 & 0.11 & 0.14 & 0.09 & 0.09 \\
\hline Further education compl., voc. adjustment & 0.00 & 0.02 & 0.01 & 0.01 & 0.00 & 0.01 \\
\hline Job-preparative measure & 0.00 & 0.00 & 0.00 & 0.00 & 0.00 & 0.00 \\
\hline Job creation scheme & 0.02 & 0.19 & 0.21 & 0.16 & 0.13 & 0.15 \\
\hline Rehabilitation measure & 0.01 & 0.01 & 0.01 & 0.03 & 0.00 & 0.01 \\
\hline \multicolumn{7}{|l|}{ Regional Context Variables } \\
\hline Cluster II & 0.40 & 0.37 & 0.61 & 0.31 & 0.23 & 0.37 \\
\hline Cluster III & 0.37 & 0.47 & 0.28 & 0.39 & 0.39 & 0.36 \\
\hline Cluster IV & 0.08 & 0.06 & 0.02 & 0.07 & 0.16 & 0.11 \\
\hline Cluster V & 0.15 & 0.10 & 0.08 & 0.23 & 0.23 & 0.16 \\
\hline
\end{tabular}

${ }^{1}$ DoR = degree of restriction

2 People with accepted degree of restriction, but no equalisation to other persons with the same DoR.

${ }^{3} \mathrm{CSE}=$ Certificate for secondary education 
Tab. A.2: Selected Descriptives for Women in West Germany

\begin{tabular}{|c|c|c|c|c|}
\hline Variables & $\begin{array}{l}\text { NON- } \\
\text { PART. }\end{array}$ & $\begin{array}{c}\text { OFFICE } \\
\text { AND } \\
\text { SERVICES }\end{array}$ & $\begin{array}{l}\text { COMM. } \\
\text { SERVICES }\end{array}$ & OTHER \\
\hline Number of observations & 34,227 & 202 & 503 & 270 \\
\hline Programme Duration (in days) & & 307.2 & 305.1 & 310.7 \\
\hline \multicolumn{5}{|l|}{ Socio-Demographic Variables } \\
\hline Age & 43.33 & 39.93 & 38.00 & 36.92 \\
\hline Married & 0.63 & 0.50 & 0.40 & 0.36 \\
\hline Number of children & 0.58 & 0.62 & 0.65 & 0.47 \\
\hline \multicolumn{5}{|l|}{ Health restrictions } \\
\hline No health restrictions & 0.73 & 0.76 & 0.79 & 0.79 \\
\hline Acc. DoR, $80 \%$ and over & 0.01 & 0.03 & 0.03 & 0.03 \\
\hline Acc. DoR, $50 \%$ to under $80 \%$ & 0.04 & 0.09 & 0.03 & 0.06 \\
\hline Acc. DoR, $30 \%$ to under $50 \%$ & 0.00 & 0.01 & 0.01 & 0.01 \\
\hline Acc. DoR, $30 \%$ to under $50 \%$, no equalis. & 0.04 & 0.01 & 0.02 & 0.01 \\
\hline Other health restrictions & 0.18 & 0.08 & 0.12 & 0.11 \\
\hline Rehabilitation attendant & 0.03 & 0.05 & 0.04 & 0.05 \\
\hline Placement restrictions & 0.18 & 0.16 & 0.13 & 0.13 \\
\hline \multicolumn{5}{|l|}{ Qualification Variables } \\
\hline \multicolumn{5}{|l|}{ Professional Training } \\
\hline Without compl. prof. training, no CSE & 0.11 & 0.01 & 0.08 & 0.11 \\
\hline Without compl. prof. training, with CSE & 0.39 & 0.29 & 0.37 & 0.41 \\
\hline Industrial training & 0.42 & 0.46 & 0.29 & 0.30 \\
\hline Full-time vocational school & 0.02 & 0.03 & 0.03 & 0.02 \\
\hline Technical school & 0.03 & 0.03 & 0.08 & 0.03 \\
\hline Polytechnic & 0.01 & 0.04 & 0.07 & 0.04 \\
\hline College, university & 0.02 & 0.13 & 0.07 & 0.08 \\
\hline \multicolumn{5}{|l|}{ Occupational group } \\
\hline Plant cultivation, breeding, fishery & 0.02 & 0.00 & 0.01 & 0.03 \\
\hline Mining, mineral extraction & 0.00 & 0.00 & 0.00 & 0.00 \\
\hline Manufacturing & 0.24 & 0.03 & 0.10 & 0.26 \\
\hline Technical professions & 0.02 & 0.05 & 0.00 & 0.03 \\
\hline Service professions & 0.71 & 0.89 & 0.88 & 0.66 \\
\hline Other professions & 0.01 & 0.03 & 0.01 & 0.02 \\
\hline \multicolumn{5}{|l|}{ Professional Rank } \\
\hline Unskilled worker & 0.17 & 0.05 & 0.15 & 0.15 \\
\hline Skilled worker & 0.06 & 0.03 & 0.03 & 0.04 \\
\hline White-collar worker, simple occupations & 0.18 & 0.27 & 0.20 & 0.13 \\
\hline White-collar worker, advanced occupations & 0.04 & 0.08 & 0.12 & 0.07 \\
\hline Other & 0.54 & 0.56 & 0.50 & 0.61 \\
\hline Qualification (with work experience) & 0.93 & 0.84 & 0.86 & 0.85 \\
\hline \multicolumn{5}{|l|}{ Career Variables } \\
\hline Duration last employment (months) & 64.12 & 32.98 & 24.82 & 21.09 \\
\hline \multicolumn{5}{|l|}{ Duration of unemployment (weeks) } \\
\hline$<13$ & 0.22 & 0.23 & 0.20 & 0.25 \\
\hline $13-52$ & 0.36 & 0.39 & 0.40 & 0.36 \\
\hline$>52$ & 0.42 & 0.38 & 0.39 & 0.40 \\
\hline Number of placement propositions & 2.99 & 8.08 & 6.42 & 6.80 \\
\hline Last contact to job center (weeks) & 2.40 & 2.57 & 2.69 & 2.29 \\
\hline \multicolumn{5}{|l|}{ Programme before unemployment } \\
\hline No further education or programme & 0.91 & 0.57 & 0.67 & 0.74 \\
\hline Further education compl., cont. education & 0.07 & 0.20 & 0.11 & 0.10 \\
\hline Further education compl., voc. adjustment & 0.00 & 0.01 & 0.00 & 0.01 \\
\hline Job-preparative measure & 0.00 & 0.00 & 0.01 & 0.00 \\
\hline Job creation scheme & 0.01 & 0.18 & 0.20 & 0.15 \\
\hline Rehabilitation measure & 0.00 & 0.03 & 0.01 & 0.01 \\
\hline \multicolumn{5}{|l|}{ Regional Context Variables } \\
\hline Cluster II & 0.34 & 0.23 & 0.35 & 0.34 \\
\hline Cluster III & 0.41 & 0.47 & 0.38 & 0.38 \\
\hline Cluster IV & 0.09 & 0.06 & 0.08 & 0.08 \\
\hline Cluster V & 0.16 & 0.23 & 0.18 & 0.20 \\
\hline
\end{tabular}

${ }^{1} \mathrm{DoR}=$ degree of restriction

${ }^{2}$ People with accepted degree of restriction, but no equalisation to other persons with the same DoR.

${ }^{3} \mathrm{CSE}=$ Certificate for secondary education 
Tab. A.3: Selected Descriptives for Men in East Germany

\begin{tabular}{|c|c|c|c|c|c|c|}
\hline Variables & $\begin{array}{l}\text { NON- } \\
\text { PART. }\end{array}$ & AGRICUL. & $\begin{array}{l}\text { CONSTR. } \\
\text { AND IN- } \\
\text { DUSTRY }\end{array}$ & $\begin{array}{c}\text { OFFICE } \\
\text { AND } \\
\text { SERVICES }\end{array}$ & $\begin{array}{c}\text { COMM. } \\
\text { SERVICES }\end{array}$ & OTHER \\
\hline Number of observations & 64788 & 925 & 416 & 202 & 410 & 971 \\
\hline Programme Duration (in days) & & 325.0 & 273.5 & 332.1 & 324.3 & 327.1 \\
\hline \multicolumn{7}{|l|}{ Socio-Demographic Variables } \\
\hline Age & 41.73 & 46.02 & 43.13 & 48.87 & 42.83 & 43.47 \\
\hline Married & 0.48 & 0.54 & 0.51 & 0.73 & 0.58 & 0.50 \\
\hline Number of children & 0.36 & 0.42 & 0.45 & 0.40 & 0.40 & 0.37 \\
\hline \multicolumn{7}{|l|}{ Health restrictions } \\
\hline No health restrictions & 0.75 & 0.79 & 0.81 & 0.75 & 0.69 & 0.77 \\
\hline Acc. DoR, $80 \%$ and over & 0.00 & 0.01 & 0.00 & 0.01 & 0.01 & 0.01 \\
\hline Acc. DoR, $50 \%$ to under $80 \%$ & 0.02 & 0.02 & 0.02 & 0.08 & 0.06 & 0.04 \\
\hline Acc. DoR, $30 \%$ to under $50 \%$ & 0.01 & 0.01 & 0.01 & 0.02 & 0.03 & 0.01 \\
\hline Acc. DoR, $30 \%$ to under $50 \%$, no equalis. & 0.02 & 0.02 & 0.01 & 0.03 & 0.02 & 0.01 \\
\hline Other health restrictions & 0.20 & 0.17 & 0.15 & 0.11 & 0.20 & 0.17 \\
\hline Rehabilitation attendant & 0.07 & 0.05 & 0.05 & 0.07 & 0.15 & 0.08 \\
\hline Placement restrictions & 0.16 & 0.11 & 0.09 & 0.14 & 0.20 & 0.14 \\
\hline \multicolumn{7}{|l|}{ Qualification Variables } \\
\hline \multicolumn{7}{|l|}{ Professional Training } \\
\hline Without compl. prof. training, no CSE & 0.06 & 0.13 & 0.09 & 0.02 & 0.04 & 0.07 \\
\hline Without compl. prof. training, with CSE & 0.17 & 0.19 & 0.19 & 0.11 & 0.18 & 0.24 \\
\hline Industrial training & 0.69 & 0.64 & 0.70 & 0.41 & 0.60 & 0.57 \\
\hline Full-time vocational school & 0.01 & 0.00 & 0.00 & 0.01 & 0.01 & 0.01 \\
\hline Technical school & 0.04 & 0.02 & 0.01 & 0.26 & 0.07 & 0.06 \\
\hline Polytechnic & 0.01 & 0.00 & 0.00 & 0.05 & 0.02 & 0.01 \\
\hline College, university & 0.03 & 0.01 & 0.00 & 0.14 & 0.08 & 0.04 \\
\hline \multicolumn{7}{|l|}{ Occupational group } \\
\hline Plant cultivation, breeding, fishery & 0.05 & 0.13 & 0.06 & 0.03 & 0.02 & 0.04 \\
\hline Mining, mineral extraction & 0.00 & 0.00 & 0.00 & 0.00 & 0.00 & 0.00 \\
\hline Manufacturing & 0.53 & 0.56 & 0.72 & 0.13 & 0.42 & 0.53 \\
\hline Technical professions & 0.06 & 0.03 & 0.02 & 0.34 & 0.09 & 0.06 \\
\hline Service professions & 0.33 & 0.27 & 0.20 & 0.50 & 0.46 & 0.35 \\
\hline Other professions & 0.03 & 0.01 & 0.00 & 0.00 & 0.01 & 0.01 \\
\hline \multicolumn{7}{|l|}{ Professional Rank } \\
\hline Unskilled worker & 0.22 & 0.38 & 0.34 & 0.15 & 0.22 & 0.28 \\
\hline Skilled worker & 0.29 & 0.20 & 0.23 & 0.15 & 0.21 & 0.19 \\
\hline White-collar worker, simple occupations & 0.04 & 0.02 & 0.02 & 0.18 & 0.07 & 0.06 \\
\hline White-collar worker, advanced occupations & 0.02 & 0.01 & 0.01 & 0.05 & 0.04 & 0.01 \\
\hline Other & 0.43 & 0.39 & 0.40 & 0.47 & 0.45 & 0.46 \\
\hline Qualification (with work experience) & 0.89 & 0.93 & 0.92 & 0.91 & 0.84 & 0.89 \\
\hline \multicolumn{7}{|l|}{ Career Variables } \\
\hline Duration last employment (months) & 55.51 & 25.38 & 19.53 & 28.04 & 18.35 & 26.52 \\
\hline \multicolumn{7}{|l|}{ Duration of unemployment (weeks) } \\
\hline$<13$ & 0.34 & 0.18 & 0.20 & 0.19 & 0.23 & 0.20 \\
\hline $13-52$ & 0.35 & 0.38 & 0.42 & 0.47 & 0.48 & 0.44 \\
\hline$>52$ & 0.31 & 0.44 & 0.38 & 0.34 & 0.29 & 0.36 \\
\hline Number of placement propositions & 3.01 & 5.41 & 6.86 & 7.08 & 6.35 & 6.01 \\
\hline Last contact to job center (weeks) & 2.79 & 2.59 & 2.41 & 2.71 & 2.65 & 2.47 \\
\hline \multicolumn{7}{|l|}{ Programme before unemployment } \\
\hline No further education or programme & 0.83 & 0.49 & 0.51 & 0.46 & 0.49 & 0.60 \\
\hline Further education compl., cont. education & 0.09 & 0.13 & 0.15 & 0.28 & 0.13 & 0.12 \\
\hline Further education compl., voc. adjustment & 0.03 & 0.06 & 0.06 & 0.04 & 0.06 & 0.04 \\
\hline Job-preparative measure & 0.00 & 0.00 & 0.00 & 0.00 & 0.01 & 0.00 \\
\hline Job creation scheme & 0.05 & 0.32 & 0.26 & 0.21 & 0.29 & 0.22 \\
\hline Rehabilitation measure & 0.01 & 0.00 & 0.00 & 0.02 & 0.01 & 0.01 \\
\hline \multicolumn{7}{|l|}{ Regional Context Variables } \\
\hline Cluster Ia & 0.22 & 0.35 & 0.15 & 0.24 & 0.11 & 0.22 \\
\hline Cluster Ib & 0.65 & 0.52 & 0.62 & 0.68 & 0.74 & 0.66 \\
\hline Cluster Ic & 0.11 & 0.12 & 0.20 & 0.08 & 0.12 & 0.07 \\
\hline Cluster II & 0.02 & 0.00 & 0.03 & 0.00 & 0.02 & 0.05 \\
\hline
\end{tabular}

${ }^{1}$ DoR $=$ degree of restriction

2 People with accepted degree of restriction, but no equalisation to other persons with the same DoR.

${ }^{3} \mathrm{CSE}=$ Certificate for secondary education 
Tab. A.4: Selected Descriptives for Women in East Germany

\begin{tabular}{|c|c|c|c|c|c|c|}
\hline Variables & $\begin{array}{l}\text { NON- } \\
\text { PART. }\end{array}$ & AGRICUL. & $\begin{array}{l}\text { CONSTR. } \\
\text { AND IN- } \\
\text { DUSTRY }\end{array}$ & $\begin{array}{c}\text { OFFICE } \\
\text { AND } \\
\text { SERVICES }\end{array}$ & $\begin{array}{c}\text { COMM. } \\
\text { SERVICES }\end{array}$ & OTHER \\
\hline Number of observations & 76512 & 986 & 193 & 645 & 1810 & 1401 \\
\hline Programme Duration (in days) & & 322.2 & 289.5 & 337.9 & 336.6 & 340.7 \\
\hline \multicolumn{7}{|l|}{ Socio-Demographic Variables } \\
\hline Age & 44.01 & 43.37 & 43.09 & 45.23 & 44.27 & 43.16 \\
\hline Married & 0.64 & 0.67 & 0.65 & 0.75 & 0.70 & 0.62 \\
\hline Number of children & 0.67 & 0.89 & 0.87 & 0.74 & 0.75 & 0.80 \\
\hline \multicolumn{7}{|l|}{ Health restrictions } \\
\hline No health restrictions & 0.80 & 0.90 & 0.87 & 0.84 & 0.83 & 0.85 \\
\hline Acc. DoR, $80 \%$ and over & 0.00 & 0.00 & 0.01 & 0.00 & 0.01 & 0.01 \\
\hline Acc. DoR, $50 \%$ to under $80 \%$ & 0.02 & 0.01 & 0.00 & 0.04 & 0.02 & 0.02 \\
\hline Acc. DoR, $30 \%$ to under $50 \%$ & 0.00 & 0.00 & 0.01 & 0.01 & 0.01 & 0.01 \\
\hline Acc. DoR, $30 \%$ to under $50 \%$, no equalis. & 0.01 & 0.00 & 0.00 & 0.01 & 0.01 & 0.00 \\
\hline Other health restrictions & 0.17 & 0.09 & 0.12 & 0.10 & 0.12 & 0.12 \\
\hline Rehabilitation attendant & 0.05 & 0.01 & 0.03 & 0.03 & 0.04 & 0.03 \\
\hline Placement restrictions & 0.12 & 0.04 & 0.06 & 0.07 & 0.10 & 0.08 \\
\hline \multicolumn{7}{|l|}{ Qualification Variables } \\
\hline \multicolumn{7}{|l|}{ Professional Training } \\
\hline Without compl. prof. training, no CSE & 0.05 & 0.09 & 0.10 & 0.00 & 0.01 & 0.03 \\
\hline Without compl. prof. training, with CSE & 0.21 & 0.23 & 0.17 & 0.12 & 0.18 & 0.20 \\
\hline Industrial training & 0.66 & 0.64 & 0.69 & 0.62 & 0.63 & 0.61 \\
\hline Full-time vocational school & 0.01 & 0.01 & 0.01 & 0.02 & 0.03 & 0.02 \\
\hline Technical school & 0.05 & 0.02 & 0.02 & 0.14 & 0.12 & 0.10 \\
\hline Polytechnic & 0.00 & 0.01 & 0.00 & 0.03 & 0.01 & 0.01 \\
\hline College, university & 0.02 & 0.01 & 0.00 & 0.06 & 0.02 & 0.03 \\
\hline \multicolumn{7}{|l|}{ Occupational group } \\
\hline Plant cultivation, breeding, fishery & 0.05 & 0.20 & 0.16 & 0.02 & 0.03 & 0.05 \\
\hline Mining, mineral extraction & 0.00 & 0.00 & 0.00 & 0.00 & 0.00 & 0.00 \\
\hline Manufacturing & 0.20 & 0.31 & 0.30 & 0.03 & 0.14 & 0.22 \\
\hline Technical professions & 0.03 & 0.03 & 0.03 & 0.10 & 0.04 & 0.07 \\
\hline Service professions & 0.70 & 0.46 & 0.52 & 0.84 & 0.79 & 0.66 \\
\hline Other professions & 0.02 & 0.00 & 0.00 & 0.00 & 0.00 & 0.00 \\
\hline \multicolumn{7}{|l|}{ Professional Rank } \\
\hline Unskilled worker & 0.21 & 0.40 & 0.41 & 0.12 & 0.21 & 0.23 \\
\hline Skilled worker & 0.16 & 0.11 & 0.15 & 0.16 & 0.16 & 0.14 \\
\hline White-collar worker, simple occupations & 0.09 & 0.02 & 0.04 & 0.15 & 0.13 & 0.12 \\
\hline White-collar worker, advanced occupations & 0.02 & 0.01 & 0.00 & 0.04 & 0.02 & 0.02 \\
\hline Other & 0.53 & 0.46 & 0.39 & 0.53 & 0.48 & 0.49 \\
\hline Qualification (with work experience) & 0.90 & 0.91 & 0.93 & 0.92 & 0.90 & 0.89 \\
\hline \multicolumn{7}{|l|}{ Career Variables } \\
\hline Duration last employment (months) & 63.44 & 25.10 & 24.89 & 37.54 & 33.54 & 30.07 \\
\hline \multicolumn{7}{|l|}{ Duration of unemployment (weeks) } \\
\hline$<13$ & 0.16 & 0.10 & 0.17 & 0.13 & 0.10 & 0.13 \\
\hline $13-52$ & 0.35 & 0.33 & 0.37 & 0.42 & 0.42 & 0.39 \\
\hline$>52$ & 0.49 & 0.58 & 0.46 & 0.45 & 0.48 & 0.48 \\
\hline Number of placement propositions & 2.77 & 4.67 & 5.40 & 6.10 & 5.57 & 5.44 \\
\hline Last contact to job center (weeks) & 2.78 & 2.57 & 2.45 & 2.54 & 2.58 & 2.65 \\
\hline \multicolumn{7}{|l|}{ Programme before unemployment } \\
\hline No further education or programme & 0.72 & 0.42 & 0.49 & 0.34 & 0.42 & 0.47 \\
\hline Further education compl., cont. education & 0.17 & 0.19 & 0.16 & 0.34 & 0.25 & 0.22 \\
\hline Further education compl., voc. adjustment & 0.03 & 0.05 & 0.07 & 0.05 & 0.05 & 0.04 \\
\hline Job-preparative measure & 0.00 & 0.00 & 0.00 & 0.00 & 0.00 & 0.00 \\
\hline Job creation scheme & 0.08 & 0.33 & 0.28 & 0.27 & 0.28 & 0.27 \\
\hline Rehabilitation measure & 0.00 & 0.00 & 0.00 & 0.00 & 0.00 & 0.00 \\
\hline \multicolumn{7}{|l|}{ Regional Context Variables } \\
\hline Cluster Ia & 0.23 & 0.35 & 0.30 & 0.17 & 0.19 & 0.27 \\
\hline Cluster Ib & 0.65 & 0.53 & 0.60 & 0.69 & 0.70 & 0.64 \\
\hline Cluster Ic & 0.10 & 0.12 & 0.09 & 0.13 & 0.10 & 0.07 \\
\hline Cluster II & 0.02 & 0.00 & 0.02 & 0.01 & 0.02 & 0.02 \\
\hline
\end{tabular}

${ }^{1}$ DoR = degree of restriction

2 People with accepted degree of restriction, but no equalisation to other persons with the same DoR.

${ }^{3} \mathrm{CSE}=$ Certificate for secondary education 
Tab. A.5: Estimation Results of the Logit Models for the Propensity SCORE For MEN IN West GeRMANY

\begin{tabular}{|c|c|c|c|c|c|}
\hline & AGRICUL. & $\begin{array}{l}\text { CONSTR. } \\
\text { AND IN- } \\
\text { DUSTRY }\end{array}$ & $\begin{array}{c}\text { OFFICE } \\
\text { AND } \\
\text { SERVICES } \\
\end{array}$ & $\begin{array}{c}\text { COMM. } \\
\text { SERVICES }\end{array}$ & POTHER \\
\hline Constant & -4.5090 & -2.0459 & -14.7072 & -1.9766 & -1.4588 \\
\hline \multicolumn{6}{|l|}{ Socio-Demographic Variables } \\
\hline Age & 0.0296 & -0.1343 & 0.3791 & -0.1129 & -0.0903 \\
\hline $\mathrm{Age}^{2}$ & -0.0004 & 0.0012 & -0.0046 & 0.0008 & 0.0008 \\
\hline Married & -0.1962 & 0.2334 & -0.2226 & -0.2582 & -0.2198 \\
\hline Number of children & 0.0821 & 0.0138 & 0.0544 & 0.1037 & 0.0470 \\
\hline German & 0.4813 & 0.7739 & 0.3909 & 0.3824 & 0.2198 \\
\hline \multicolumn{6}{|l|}{ Health restrictions } \\
\hline No health restrictions & Ref. & Ref. & Ref. & Ref. & Ref. \\
\hline Acc. DoR ${ }^{1}, 80 \%$ and over & 1.0175 & -0.1815 & 2.6592 & 0.9154 & 0.8374 \\
\hline Acc. DoR, $50 \%$ to under $80 \%$ & 0.6903 & -0.2525 & 2.1295 & 1.0849 & 0.7921 \\
\hline Acc. DoR, $30 \%$ to under $50 \%$ & 1.2822 & - & 2.2650 & 1.6448 & 1.0191 \\
\hline Acc. DoR, $30 \%$ to under $50 \%$, no equalis. ${ }^{2}$ & 0.4658 & -0.1619 & 1.5272 & 0.2676 & -0.0430 \\
\hline Other health restrictions & 0.0007 & -0.5748 & 0.3054 & -0.0625 & 0.0104 \\
\hline \multicolumn{6}{|l|}{ Qualification Variables } \\
\hline \multicolumn{6}{|l|}{ Professional training } \\
\hline Without compl. prof. training, no CSE & Ref. & Ref. & Ref. & Ref. & Ref. \\
\hline Without compl. prof. training, with CSE & -0.4973 & -0.2519 & 0.0767 & -0.1785 & -0.2244 \\
\hline Industrial training & -0.8328 & -0.9076 & 0.7825 & -0.4150 & -0.6079 \\
\hline Full-time vocational school & -2.2360 & -0.7638 & 0.5245 & 0.1831 & -0.8342 \\
\hline Technical school & -0.6101 & -1.9566 & 1.8069 & 0.8077 & -0.3926 \\
\hline Polytechnic & -1.1617 & -1.2058 & 1.5514 & 1.5481 & 0.2834 \\
\hline College, University & -1.2767 & -1.6570 & 1.5608 & 1.1832 & 0.3560 \\
\hline \multicolumn{6}{|l|}{ Occupational group } \\
\hline Plant cultivation, breeding, fishery & 0.7547 & -0.2927 & 0.5320 & -0.5022 & -0.2250 \\
\hline Mining, mineral extraction & -0.1697 & -0.2687 & - & - & -1.0362 \\
\hline Manufacturing & Ref. & Ref. & Ref. & Ref. & Ref. \\
\hline Technical professions & -1.1560 & -0.3301 & 1.1658 & -0.9419 & -0.6920 \\
\hline Service professions & -0.3911 & -0.9058 & 0.8755 & 0.2073 & -0.3893 \\
\hline Other professions & 0.1087 & -0.0414 & - & 0.0509 & 0.1483 \\
\hline \multicolumn{6}{|l|}{ Professional rank } \\
\hline Unskilled worker & Ref. & Ref. & Ref. & Ref. & Ref. \\
\hline Skilled worker & -0.9516 & -0.6308 & -0.1782 & -0.2041 & -0.2274 \\
\hline White-collar worker, simple occupations & -0.9201 & -0.3070 & 0.9784 & 0.7277 & 0.1837 \\
\hline White-collar worker, advanced occupations & -0.4016 & -0.9263 & 1.2236 & 0.6425 & 0.2038 \\
\hline Other & -0.3683 & -0.1285 & 0.4315 & 0.5479 & 0.1596 \\
\hline Qualification (with work experience) & -0.1010 & -0.0272 & -0.6922 & -0.3797 & -0.5170 \\
\hline \multicolumn{6}{|l|}{ Career Variables } \\
\hline Duration of last employment (months) & -0.0060 & -0.0037 & -0.0045 & -0.0042 & -0.0042 \\
\hline \multicolumn{6}{|l|}{ Duration of unemployment (weeks) } \\
\hline Up to 13 weeks & Ref. & Ref. & Ref. & Ref. & Ref. \\
\hline Between 13 and 52 weeks & 0.3618 & 0.1339 & 0.1228 & 0.1566 & 0.0478 \\
\hline More than 52 weeks & 0.4661 & 0.1087 & 0.2744 & 0.1279 & 0.1306 \\
\hline Number of placement propositions & 0.0488 & 0.0390 & 0.0548 & 0.0422 & 0.0509 \\
\hline Last contact to job center (weeks) & -0.0868 & -0.0427 & 0.1005 & 0.0370 & 0.0481 \\
\hline Rehabilitation attendant & -0.1213 & 0.3637 & 0.0981 & 0.0664 & -0.6723 \\
\hline Placement restrictions & -0.5594 & 0.1139 & -0.9824 & -0.2758 & -0.0975 \\
\hline \multicolumn{6}{|l|}{ Programme before unemployment } \\
\hline No further education or programme & Ref. & Ref. & Ref. & Ref. & Ref. \\
\hline Further education compl., cont. education & 0.2545 & 0.4914 & 0.3483 & 0.0440 & 0.1234 \\
\hline Further education compl., voc. adjustment & 0.7916 & 1.3185 & 0.0651 & - & 0.7083 \\
\hline Job-preparative measure & - & - & - & - & 0.4281 \\
\hline Job creation scheme & 1.8566 & 2.3925 & 2.2831 & 2.1205 & 2.1139 \\
\hline Rehabilitation measure & -0.3244 & -0.3238 & 0.2913 & -1.3737 & 0.2296 \\
\hline \multicolumn{6}{|l|}{ Regional Context Variables } \\
\hline Cluster II & 0.0350 & 0.8558 & -1.0783 & -1.2007 & -0.3589 \\
\hline Cluster III & 0.3023 & 0.0440 & -0.6491 & -0.5698 & -0.2780 \\
\hline Cluster IV & -0.0778 & -0.5322 & -0.9304 & 0.0819 & 0.1881 \\
\hline Cluster V & Ref. & Ref. & Ref. & Ref. & Ref. \\
\hline Number of Observations & 444657 & 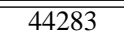 & 43097 & 43907 & 444829 \\
\hline Log-Likelihood & -2641.6 & -1788.1 & -690.5 & -1630.7 & -3325.6 \\
\hline $\mathrm{R}-2$ & 0.151 & 0.166 & 0.224 & 0.139 & 0.112 \\
\hline F-Test & 942.6 & 711.1 & 399.1 & 526.1 & 841.3 \\
\hline
\end{tabular}

Bold letters indicate significance at the $1 \%$ level. Italic letters refer to the $5 \%$ level.

${ }^{1} \mathrm{DoR}=$ degree of restriction.

2 People with accepted degree of restriction, but no equalisation to other persons with the same DoR.

${ }^{3} \mathrm{CSE}=$ Certificate for secondary education

${ }^{4}$ Cluster according to the classification by Blien et al. (2004). 
Tab. A.6: Estimation Results of the Logit Models For the PROPENSITY SCORE FOR WOMEN IN WEST GERMANY

\begin{tabular}{|c|c|c|c|}
\hline & $\begin{array}{c}\text { OFFICE } \\
\text { AND } \\
\text { SERVICES }\end{array}$ & $\begin{array}{c}\text { COMM. } \\
\text { SERVICES }\end{array}$ & OTHER \\
\hline Constant & -10.8847 & -4.0484 & -2.8853 \\
\hline \multicolumn{4}{|l|}{ Socio-Demographic Variables } \\
\hline Age & 0.1432 & -0.0184 & -0.0337 \\
\hline $\mathrm{Age}^{2}$ & -0.0020 & -0.0001 & 0.0000 \\
\hline Married & -0.0555 & -0.4877 & -0.5266 \\
\hline Number of children & -0.0584 & 0.0991 & -0.1484 \\
\hline German & 0.2172 & 0.2534 & 0.0660 \\
\hline \multicolumn{4}{|l|}{ Health restrictions } \\
\hline No health restrictions & Ref. & Ref. & Ref. \\
\hline Acc. DoR ${ }^{1}, 80 \%$ and over & 1.6533 & 1.2490 & 1.1843 \\
\hline Acc. DoR, $50 \%$ to under $80 \%$ & 1.2609 & 0.1901 & 0.8155 \\
\hline Acc. DoR, $30 \%$ to under $50 \%$ & 2.6829 & 1.6893 & 1.9266 \\
\hline Acc. DoR, $30 \%$ to under $50 \%$, no equalis. ${ }^{2}$ & -0.1754 & 0.0613 & -0.1396 \\
\hline Other health restrictions & -0.5043 & 0.0392 & -0.1831 \\
\hline \multicolumn{4}{|l|}{ Qualification Variables } \\
\hline \multicolumn{4}{|l|}{ Professional training } \\
\hline Without compl. prof. training, no CSE & Ref. & Ref. & Ref. \\
\hline Without compl. prof. training, with CSE & 1.4281 & 0.2030 & 0.1662 \\
\hline Industrial training & 1.4096 & -0.1961 & -0.1883 \\
\hline Full-time vocational school & 1.2480 & 0.0993 & -0.3989 \\
\hline Technical school & 1.2967 & 1.0363 & 0.2617 \\
\hline Polytechnic & 1.9382 & 1.7607 & 1.0906 \\
\hline College, University & 2.6014 & 0.7199 & 0.9856 \\
\hline \multicolumn{4}{|l|}{ Occupational group } \\
\hline Plant cultivation, breeding, fishery & - & -0.3153 & 0.1718 \\
\hline Mining, mineral extraction & - & - & - \\
\hline Manufacturing & Ref. & Ref. & Ref. \\
\hline Technical professions & 2.1652 & -1.5239 & -0.2572 \\
\hline Service professions & 1.7365 & 0.7999 & -0.3822 \\
\hline Other professions & 2.7255 & 0.3314 & -0.2270 \\
\hline \multicolumn{4}{|l|}{ Professional rank } \\
\hline Unskilled worker & Ref. & Ref. & Ref. \\
\hline Skilled worker & 0.3798 & -0.3085 & -0.1599 \\
\hline White-collar worker, simple occupations & 0.9857 & 0.0576 & -0.0256 \\
\hline White-collar worker, advanced occupations & 0.6057 & 0.6116 & 0.5002 \\
\hline Other & 0.6401 & -0.0642 & 0.3818 \\
\hline Qualification (with work experience) & -0.5613 & -0.2914 & -0.2246 \\
\hline \multicolumn{4}{|l|}{ Career Variables } \\
\hline Duration of last employment (months) & -0.0011 & -0.0036 & -0.0052 \\
\hline \multicolumn{4}{|l|}{ Duration of unemployment (weeks) } \\
\hline Up to 13 weeks & Ref. & Ref. & Ref. \\
\hline Between 13 and 52 weeks & -0.0406 & 0.1764 & -0.0637 \\
\hline More than 52 weeks & -0.1897 & 0.1289 & 0.0470 \\
\hline Number of placement propositions & 0.0639 & 0.0405 & 0.0519 \\
\hline Last contact to job center (weeks) & 0.0715 & 0.0868 & -0.0107 \\
\hline Rehabilitation attendant & -0.2866 & 0.0587 & 0.4787 \\
\hline Placement restrictions & -0.2261 & -0.2235 & -0.4517 \\
\hline \multicolumn{4}{|l|}{ Programme before unemployment } \\
\hline No further education or programme & Ref. & Ref. & Ref. \\
\hline Further education compl., cont. education & 1.0745 & 0.4635 & 0.1449 \\
\hline Further education compl., voc. adjustment & 0.8883 & 0.2137 & 0.7757 \\
\hline Job-preparative measure & - & 3.0067 & 1.9089 \\
\hline Job creation scheme & 3.2762 & 3.0801 & 2.6577 \\
\hline Rehabilitation measure & 2.4833 & 0.4374 & 0.1713 \\
\hline \multicolumn{4}{|l|}{ Regional Context Variables } \\
\hline Cluster II & -1.1530 & -0.4614 & -0.4831 \\
\hline Cluster III & -0.4413 & -0.4805 & -0.4413 \\
\hline Cluster IV & -0.9771 & -0.3191 & -0.3983 \\
\hline Cluster V & Ref. & Ref. & Ref. \\
\hline Number of Observations & 33808 & 34722 & 34489 \\
\hline Log-Likelihood & -978.6 & -2155.6 & -1366.9 \\
\hline Adj. $R^{2}$ & 0.208 & 0.180 & 0.134 \\
\hline$F$-Test & 514.1 & 947.4 & 423.0 \\
\hline
\end{tabular}

Bold letters indicate significance at the $1 \%$ level. Italic letters refer to the $5 \%$ level.

${ }^{1}$ DoR $=$ degree of restriction.

2 People with accepted degree of restriction, but no equalisation to other persons with the same DoR.

${ }^{3} \mathrm{CSE}=$ Certificate for secondary education

${ }^{4}$ Cluster according to the classification by Blien et al. (2004). 
Tab. A.7: Estimation Results of the Logit Models for the Propensity SCORE For MEN In EAST GERMANY

\begin{tabular}{|c|c|c|c|c|c|}
\hline & AGRICUL. & $\begin{array}{l}\text { CONSTR. } \\
\text { AND IN- } \\
\text { DUSTRY }\end{array}$ & $\begin{array}{c}\text { OFFICE } \\
\text { AND } \\
\text { SERVICES }\end{array}$ & $\begin{array}{c}\text { COMM. } \\
\text { SERVICES }\end{array}$ & $\overline{\text { OTHER }}$ \\
\hline Constant & -8.2748 & -9.5586 & -13.5752 & -7.7192 & -5.8072 \\
\hline \multicolumn{6}{|l|}{ Socio-Demographic Variables } \\
\hline Age & 0.1404 & 0.1422 & $\mathbf{0 . 2 5 3 7}$ & 0.0405 & 0.0536 \\
\hline $\mathrm{Age}^{2}$ & -0.0012 & -0.0015 & -0.0027 & -0.0006 & -0.0005 \\
\hline Married & 0.1750 & 0.2778 & 0.7052 & 0.6680 & 0.1540 \\
\hline Number of children & -0.0003 & -0.0185 & -0.0923 & -0.1112 & -0.0355 \\
\hline German & 0.9722 & 0.9294 & & 0.4182 & 0.2826 \\
\hline \multicolumn{6}{|l|}{ Health restrictions } \\
\hline No health restrictions & Ref. & Ref. & Ref. & Ref. & Ref. \\
\hline Acc. DoR ${ }^{1}, 80 \%$ and over & 0.7313 & - & 1.0624 & 0.9844 & 0.3286 \\
\hline Acc. DoR, $50 \%$ to under $80 \%$ & 0.1230 & 0.3058 & 1.2961 & 0.7323 & 0.4997 \\
\hline Acc. DoR, $30 \%$ to under $50 \%$ & -0.0321 & 0.9936 & 0.8507 & 0.9713 & 0.5456 \\
\hline Acc. DoR, $30 \%$ to under $50 \%$, no equalis. ${ }^{2}$ & 0.1819 & -0.1677 & 0.6446 & 0.1971 & -0.6727 \\
\hline Other health restrictions & -0.1835 & -0.0607 & -0.3975 & -0.1103 & -0.2133 \\
\hline \multicolumn{6}{|l|}{ Qualification Variables } \\
\hline \multicolumn{6}{|l|}{ Professional training } \\
\hline Without compl. prof. training, no CSE & Ref. & Ref. & Ref. & Ref. & Ref. \\
\hline Without compl. prof. training, with CSE & -0.1993 & 0.0082 & 0.7288 & 0.5236 & 0.3536 \\
\hline Industrial training & -0.4028 & -0.0537 & 0.6616 & 0.4050 & -0.1207 \\
\hline Full-time vocational school & -1.1763 & - & 0.7572 & 0.9366 & -0.0298 \\
\hline Technical school & -0.7256 & -0.9740 & 1.9463 & 1.0078 & 0.4512 \\
\hline Polytechnic & -1.2676 & -0.5647 & 1.2524 & 1.2241 & 0.1479 \\
\hline College, University & -1.0406 & -2.3433 & 1.5007 & 1.2085 & 0.3227 \\
\hline \multicolumn{6}{|l|}{ Occupational group } \\
\hline Plant cultivation, breeding, fishery & 0.4311 & -0.4405 & 0.7232 & -0.6927 & -0.4147 \\
\hline Mining, mineral extraction & -0.2213 & - & - & - & -0.9264 \\
\hline Manufacturing & Ref. & Ref. & Ref. & Ref. & Ref. \\
\hline Technical professions & -0.5769 & -0.7692 & 2.0272 & -0.0203 & -0.3332 \\
\hline Service professions & -0.3614 & -0.8173 & 1.5137 & 0.3114 & -0.1208 \\
\hline Other professions & -0.8095 & -2.5447 & - & -1.1155 & -1.1386 \\
\hline \multicolumn{6}{|l|}{ Professional rank } \\
\hline Unskilled worker & Ref. & Ref. & Ref. & Ref. & Ref. \\
\hline Skilled worker & -0.2621 & -0.1943 & 0.0823 & 0.1961 & -0.2162 \\
\hline White-collar worker, simple occupations & -0.5796 & -0.0050 & 0.8196 & 0.6719 & 0.3583 \\
\hline White-collar worker, advanced occupations & -0.4724 & 0.0520 & 0.1988 & 0.8298 & -0.6402 \\
\hline Other & -0.0491 & -0.0736 & 0.1469 & 0.3534 & 0.0624 \\
\hline Qualification (with work experience) & 0.0340 & 0.0726 & -0.5968 & -0.5560 & -0.2526 \\
\hline \multicolumn{6}{|l|}{ Career Variables } \\
\hline Duration of last employment (months) & -0.0033 & -0.0046 & -0.0047 & -0.0058 & -0.0032 \\
\hline \multicolumn{6}{|l|}{ Duration of unemployment (weeks) } \\
\hline Up to 13 weeks & Ref. & Ref. & Ref. & Ref. & Ref. \\
\hline Between 13 and 52 weeks & 0.4516 & 0.5849 & 0.2067 & 0.2123 & 0.4993 \\
\hline More than 52 weeks & 0.6017 & 0.6374 & -0.1582 & -0.1864 & 0.4252 \\
\hline Number of placement propositions & 0.0478 & 0.0563 & 0.0865 & 0.0599 & 0.0619 \\
\hline Last contact to job center (weeks) & -0.1348 & -0.1612 & -0.0797 & -0.0580 & -0.1404 \\
\hline Rehabilitation attendant & -0.0539 & 0.1741 & 0.1138 & 0.8264 & 0.2646 \\
\hline Placement restrictions & -0.3779 & -0.6037 & -0.3717 & -0.1578 & -0.2246 \\
\hline \multicolumn{6}{|l|}{ Programme before unemployment } \\
\hline No further education or programme & Ref. & Ref. & Ref. & Ref. & Ref. \\
\hline Further education compl., cont. education & 0.5840 & 0.5980 & 1.1618 & 0.5393 & 0.2033 \\
\hline Further education compl., voc. adjustment & 0.7988 & 0.7730 & 0.2532 & 1.0237 & 0.3476 \\
\hline Job-preparative measure & - & 2.0179 & - & 2.0594 & 0.0596 \\
\hline Job creation scheme & 1.7722 & 1.7151 & 1.6850 & 2.2508 & 1.4818 \\
\hline Rehabilitation measure & - & 0.3156 & 1.4364 & 0.2399 & 0.6264 \\
\hline \multicolumn{6}{|l|}{ Regional Context Variables } \\
\hline Cluster Ia & Ref. & Ref. & Ref. & Ref. & Ref. \\
\hline Cluster Ib & -0.7175 & 0.2881 & -0.3000 & 0.6637 & -0.0922 \\
\hline Cluster Ic & -0.4215 & 0.9103 & -0.7914 & 0.5424 & -0.6073 \\
\hline Cluster II & -1.8884 & 0.8778 & - & 0.6829 & 0.7615 \\
\hline Number of Observations & 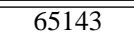 & 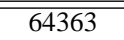 & 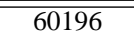 & 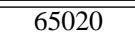 & 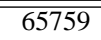 \\
\hline Log-Likelihood & -4171.0 & -2196.1 & -1050.4 & -2154.7 & -4612.0 \\
\hline $\mathrm{R}-2$ & 0.141 & 0.126 & 0.223 & 0.133 & 0.088 \\
\hline F-Test & 1365.7 & 631.7 & 604.1 & 662.5 & 886.0 \\
\hline
\end{tabular}

Bold letters indicate significance at the $1 \%$ level. Italic letters refer to the $5 \%$ level.

${ }^{1} \mathrm{DoR}=$ degree of restriction.

2 People with accepted degree of restriction, but no equalisation to other persons with the same DoR.

${ }^{3} \mathrm{CSE}=$ Certificate for secondary education

${ }^{4}$ Cluster according to the classification by Blien et al. (2004). 
Tab. A.8: Estimation Results of the Logit Models for the Propensity Score for WOMEN IN EAST GERMANY

\begin{tabular}{|c|c|c|c|c|c|}
\hline & AGRICUL. & $\begin{array}{l}\text { CONSTR. } \\
\text { AND IN- } \\
\text { DUSTRY }\end{array}$ & $\begin{array}{c}\text { OFFICE } \\
\text { AND } \\
\text { SERVICES }\end{array}$ & $\begin{array}{c}\text { COMM. } \\
\text { SERVICES }\end{array}$ & OTHER \\
\hline Constant & -8.3115 & -7.3101 & -17.9453 & -11.0899 & -7.4834 \\
\hline \multicolumn{6}{|l|}{ Socio-Demographic Variables } \\
\hline Age & 0.1646 & 0.1095 & 0.2713 & 0.1896 & $\mathbf{0 . 1 3 5 7}$ \\
\hline $\mathrm{Age}^{2}$ & -0.0019 & -0.0012 & -0.0030 & -0.0021 & -0.0016 \\
\hline Married & 0.1734 & 0.0965 & 0.3118 & 0.1677 & -0.0951 \\
\hline Number of children & -0.0079 & 0.0391 & -0.0247 & -0.0443 & -0.0068 \\
\hline German & 1.2282 & 0.1296 & 0.9727 & 0.9592 & 0.2932 \\
\hline \multicolumn{6}{|l|}{ Health restrictions } \\
\hline No health restrictions & Ref. & Ref. & Ref. & Ref. & Ref. \\
\hline Acc. DoR ${ }^{1}, 80 \%$ and over & 0.5151 & 1.3060 & 0.4847 & 1.2810 & $\mathbf{1 . 3 1 1 7}$ \\
\hline Acc. DoR, $50 \%$ to under $80 \%$ & -0.4661 & - & 1.4311 & 0.5698 & 0.5660 \\
\hline Acc. DoR, $30 \%$ to under $50 \%$ & -0.0995 & 0.6024 & 1.0580 & 0.9809 & 0.7660 \\
\hline Acc. DoR, $30 \%$ to under $50 \%$, no equalis. ${ }^{2}$ & -0.4257 & - & -0.1513 & 0.3423 & -0.7409 \\
\hline Other health restrictions & -0.3801 & -0.0696 & 0.0203 & -0.1429 & -0.0935 \\
\hline \multicolumn{6}{|l|}{ Qualification Variables } \\
\hline \multicolumn{6}{|l|}{ Professional training } \\
\hline Without compl. prof. training, no CSE & Ref. & Ref. & Ref. & Ref. & Ref. \\
\hline Without compl. prof. training, with CSE & -0.1973 & -0.7454 & 2.8098 & 1.1480 & 0.4957 \\
\hline Industrial training & -0.2955 & -0.4954 & 3.1291 & 1.1850 & 0.3712 \\
\hline Full-time vocational school & -0.1436 & -0.5663 & 3.5078 & 1.9609 & 0.7458 \\
\hline Technical school & -1.0249 & -1.0713 & 3.8222 & 2.0607 & 1.1572 \\
\hline Polytechnic & 0.1174 & - & 4.2966 & 1.8746 & 0.8370 \\
\hline College, University & -0.6146 & - & 4.1203 & 1.6008 & 1.1025 \\
\hline \multicolumn{6}{|l|}{ Occupational group } \\
\hline Plant cultivation, breeding, fishery & 0.7666 & 0.5567 & 0.8609 & -0.4426 & -0.3304 \\
\hline Mining, mineral extraction & - & - & - & - & - \\
\hline Manufacturing & Ref. & Ref. & Ref. & Ref. & Ref. \\
\hline Technical professions & -0.1984 & -0.0814 & 2.1028 & -0.0027 & 0.3317 \\
\hline Service professions & -0.6008 & -0.4644 & 1.7419 & 0.4004 & -0.2090 \\
\hline Other professions & -2.1141 & - & - & -0.8522 & -0.9722 \\
\hline \multicolumn{6}{|l|}{ Professional rank } \\
\hline Unskilled worker & Ref. & Ref. & Ref. & Ref. & Ref. \\
\hline Skilled worker & -0.3874 & -0.3283 & 0.7162 & 0.2401 & 0.1468 \\
\hline White-collar worker, simple occupations & -1.1101 & -0.7485 & 0.8690 & 0.3714 & 0.5205 \\
\hline White-collar worker, advanced occupations & -0.6226 & - & 0.7576 & 0.0554 & -0.0237 \\
\hline Other & -0.0863 & -0.4287 & 0.6151 & 0.1320 & 0.2311 \\
\hline Qualification (with work experience) & -0.0233 & 0.2537 & 0.0397 & -0.1753 & -0.2035 \\
\hline \multicolumn{6}{|l|}{ Career Variables } \\
\hline Duration of last employment (months) & -0.0038 & -0.0036 & -0.0018 & -0.0025 & -0.0032 \\
\hline \multicolumn{6}{|l|}{ Duration of unemployment (weeks) } \\
\hline Up to 13 weeks & Ref. & Ref. & Ref. & Ref. & Ref. \\
\hline Between 13 and 52 weeks & 0.1846 & -0.1683 & 0.0900 & 0.4047 & 0.1262 \\
\hline More than 52 weeks & 0.4296 & -0.3131 & -0.1725 & 0.2016 & 0.0354 \\
\hline Number of placement propositions & 0.0720 & 0.0945 & 0.0871 & 0.0844 & 0.0883 \\
\hline Last contact to job center (weeks) & -0.0903 & -0.1270 & -0.0665 & -0.0624 & -0.0412 \\
\hline Rehabilitation attendant & -0.3401 & 0.4405 & 0.1995 & 0.3138 & 0.0668 \\
\hline Placement restrictions & -0.3940 & -0.3174 & -0.6241 & -0.1234 & -0.2779 \\
\hline \multicolumn{6}{|l|}{ Programme before unemployment } \\
\hline No further education or programme & Ref. & Ref. & Ref. & Ref. & Ref. \\
\hline Further education compl., cont. education & 0.3164 & 0.1885 & 1.0771 & 0.6341 & 0.3466 \\
\hline Further education compl., voc. adjustment & 0.7365 & 0.8097 & 0.8346 & 0.5587 & 0.3103 \\
\hline Job-preparative measure & 0.7493 & - & - & 1.1397 & - \\
\hline Job creation scheme & 1.3215 & 1.1128 & 2.0433 & 1.6684 & 1.4558 \\
\hline Rehabilitation measure & 0.7830 & - & 0.5727 & 0.4027 & 0.1661 \\
\hline \multicolumn{6}{|l|}{ Regional Context Variables } \\
\hline Cluster Ia & Ref. & Ref. & Ref. & Ref. & Ref. \\
\hline Cluster Ib & -0.6175 & -0.3887 & 0.1607 & 0.1800 & -0.3009 \\
\hline Cluster Ic & -0.4307 & -0.5747 & 0.2994 & -0.0548 & -0.8413 \\
\hline Cluster II & -2.9446 & -0.2383 & -0.6426 & 0.4739 & -0.0499 \\
\hline Number of Observations & 77456 & 70413 & 75868 & 78280 & 77777 \\
\hline Log-Likelihood & -4602.3 & -1224.2 & -3112.0 & -7635.1 & -6387.1 \\
\hline $\mathrm{R}-2$ & 0.129 & 0.080 & 0.163 & 0.113 & 0.089 \\
\hline F-Test & 1360.2 & 214.3 & 1210.6 & 1944.0 & 1257.2 \\
\hline
\end{tabular}

Bold letters indicate significance at the $1 \%$ level. Italic letters refer to the $5 \%$ level.

${ }^{1} \mathrm{DoR}=$ degree of restriction.

2 People with accepted degree of restriction, but no equalisation to other persons with the same DoR.

${ }^{3} \mathrm{CSE}=$ Certificate for secondary education

${ }^{4}$ Cluster according to the classification by Blien et al. (2004). 


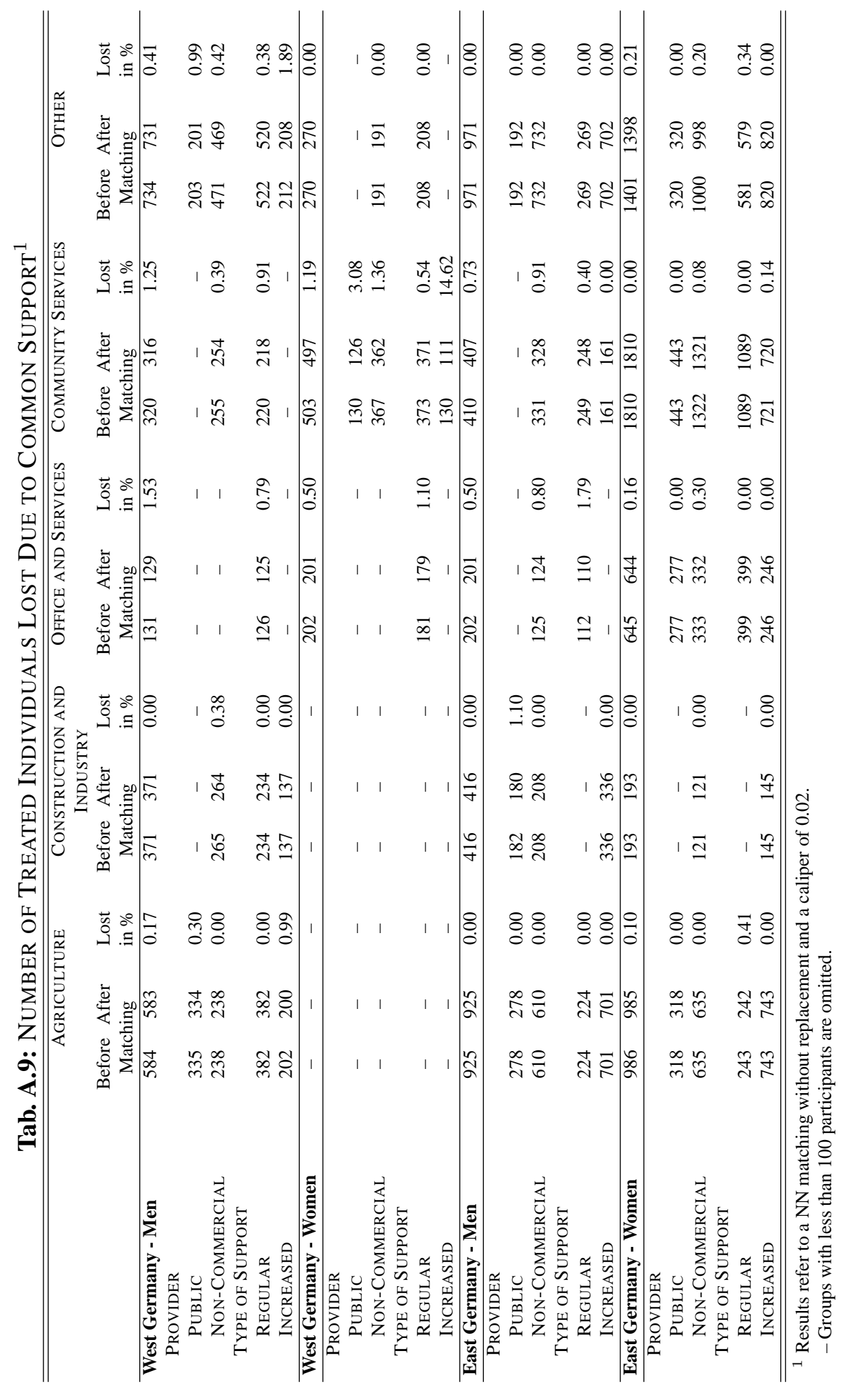


Summary (200 words): Job creation schemes (JCS) have been one important programme of active labour market policy (ALMP) in Germany for a long time. They aim at the re-integration of hard-to-place unemployed individuals into regular employment. A thorough microeconometric evaluation of these programmes was hindered by the fact, that available survey datasets have been too small to account for a possible occurrence of effect heterogeneity. However, identifying effect heterogeneity can help to improve the design and implementation of future programmes. Hence, we use administrative data of the Federal Employment Agency, containing over 11,000 participants to analyse the employment effects of JCS on an individual level. We focus explicitly on effect heterogeneity caused by differences in the implementation of programmes, whereas we analysed these effects with respect to group-specific and regional heterogeneity in a previous paper. At first, we evaluate the effects with respect to the economic sector in which the JCS are accomplished. Second, we analyse if different types of support lead to different effects. Finally, we examine if there are varying effects which can be attributed to different implementing institutions. The results are rather discouraging and show that JCS are in general not able to improve the re-integration chances of participants into regular employment. 